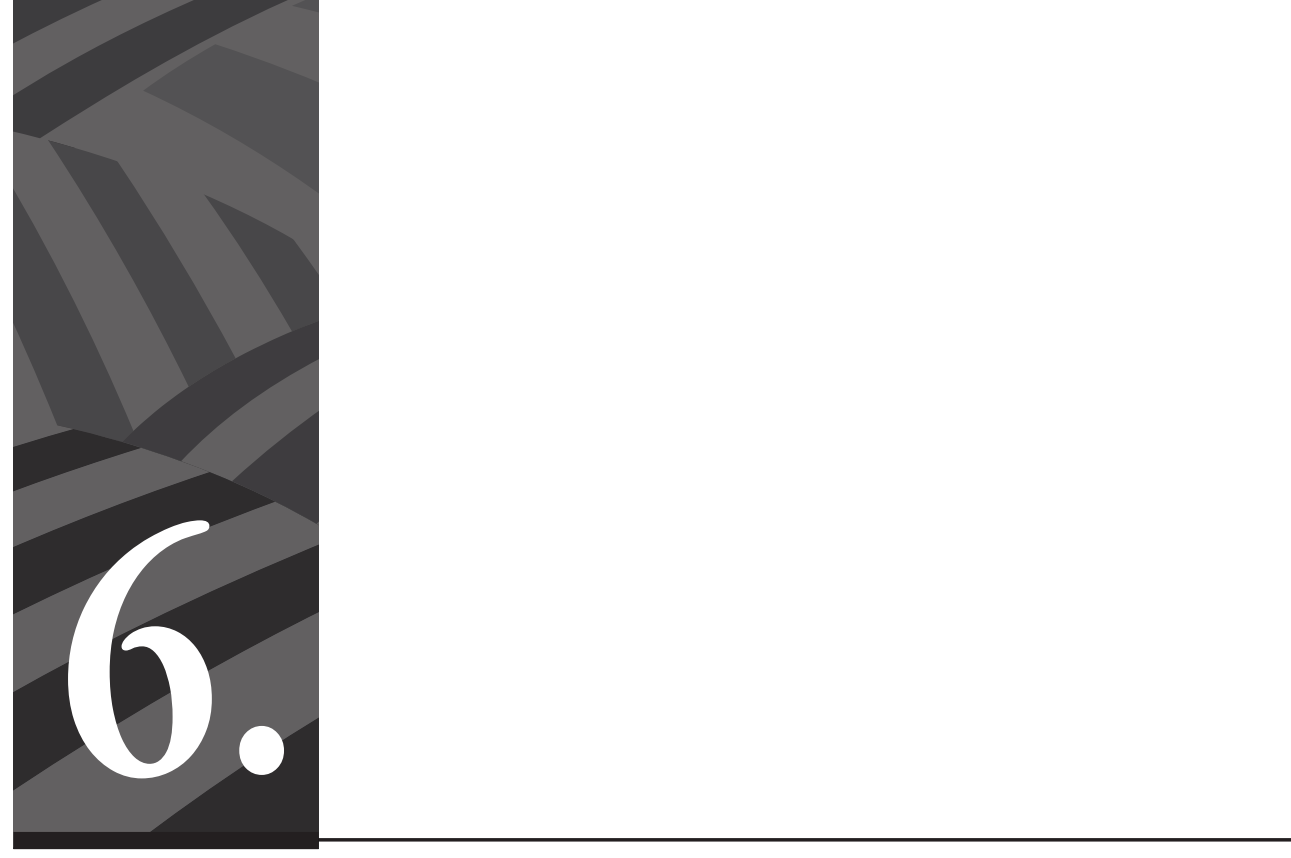

Conflictos socioambientales por neoextractivismo en el oriente del departamento de Antioquia 


\section{Conflictos socioambientales por neoextractivismo en el oriente del departamento de Antioquia ${ }^{\S}$}

Por Nathalia Ávila Escobar* y Jorge Montenegro Gómez ${ }^{* *}$

Resumen: el siguiente artículo es una aproximación a los conflictos socioambientales por neoextractivismo en el oriente del departamento de Antioquia, Colombia, por la construcción de grandes, pequeñas y microcentrales hidroeléctricas y por la gran minería transnacional. Estas reflexiones se engloban en deliberaciones teóricas sobre el neodesarrollismo neoliberal y el "consenso de las commodities", y sobre la justicia, la deuda ambiental y los significados otros de la naturaleza. El artículo, por lo tanto, busca dar un panorama de estos conflictos socioambientales a partir de las relaciones de poder y de las relaciones de movilización social contra este modelo extractivo.

Palabras clave: neoextractivismo, movilización social y conflictos socioambientales

$\S \quad$ Las reflexiones aquí presentadas hacen parte de la tesis de maestría en geografía de Nathalia Ávila Escobar presentada en la Universidad Federal de Paraná, en Curitiba, Brasil, titulada "La naturaleza-vida se cuida y se defiende: conflictos por neoextractivismo en el oriente del departamento de Antioquia, Colombia”. Esta tesis de maestría fue orientada por el profesor doctor Jorge Montenegro Gómez y apoyada por el Programa Estudante-Convênio de Pós-graduação - PEC-PG- da CAPES/CNPq, Brasil.

* Socióloga de la Universidad Externado de Colombia y magíster en geografía de la Universidad Federal de Paraná en Curitiba Brasil. Correo electrónico: nataliavila1 @ hotmail.com

** Geógrafo formado por la Universidad de Barcelona (Estado español). Profesor de los cursos de grado y posgrado en Geografía de la Universidad Federal do Paraná (Curitiba, Brasil). Correo electrónico: jorgemon@ufpr.br 


\section{Socio-environmental conflicts over neo- extractivism in the east of the state of Antioquia}

Abstract: The following article is an approximation to the socioenvironmental conflicts by neo-extractivism in the East of the department of Antioquia, Colombia, for the construction of hydroelectric power plants and by the great transnational mining. These reflections are embedded in theoretical considerations on the "neoliberalism neodevelopment" and the "consensus of the Commodities" and on the justice, the environmental debt and the other meanings of the nature. The article therefore seeks to give an overview of these socioenvironmental conflicts, based on power relations and social mobilization relations against this extractive model.

Key words: neo-extractivism, social mobilization and social-environmental conflicts.

Cómo citar este artículo: Ávila Escobar, Nathalia y Montenegro Gómez, Jorge (2017). Conflictos socioambientales por neoextractivismo en el oriente del departamento de Antioquia. Revista Controversia, 208, 225-278.

Fecha de recepción: 3 de febrero del 2017

Fecha de aprobación: 10 de mayo del 2017

\section{Introducción}

$\mathrm{E}$ l objetivo de este artículo es aproximarnos a los conflictos socioambientales por neoextractivismo en el Oriente antioqueño, a partir de las relaciones sociales actuales de poder y de movilización social, teniendo en cuenta las reflexiones teóricas sobre el neodesarrollismo neoliberal y la justicia ambiental. Para realizar este objetivo, dividimos el texto en seis partes: en la primera, haremos un breve acercamiento a la formación espacial e histórica del Oriente antioqueño, en clave de extractivismo y movilización social; en la segunda, nos aproximaremos a los conflictos socioambientales actuales en el 
Oriente antioqueño; en la tercera, describiremos algunos casos concretos de los conflictos alrededor de la construcción de hidroeléctricas y de adjudicación de títulos mineros en el Oriente; en la cuarta, buscaremos comprender las relaciones de poder del neoextractivismo a partir del neoliberalismo y del neodesarrollismo neoliberal; la quinta nos ayudará a aproximarnos a las movilizaciones sociales contra este modelo neoextractivo a partir de la justicia y la deuda ambiental y de los significados otros de la naturaleza; y finalmente, en la sexta parte presentaremos algunas consideraciones finales sobre el neoextractivismo, la movilización social y los conflictos socioambientales.

\section{La formación espacial e histórica del Oriente antioqueño: extractivismo y movilización social}

La subregión del Oriente antioqueño tiene algunas especificidades en las dinámicas extractivas que se relacionan con la formación espacial e histórica de este territorio. En primera instancia, es importante señalar que esta región fue considerada durante mucho tiempo la "despensa agrícola de Antioquia”, dada la variedad de frutas, hortalizas, tubérculos y de otros productos que producía esta región (Iner, 2003). Sus veintitrés municipios eran, por lo tanto, territorios principalmente campesinos en donde los cultivos de café, plátano, maíz, frijol, tomate, papa y yuca se constituían como las actividades sociales, culturales y económicas más importantes de la población, junto con la pesca y la minería artesanal (Olaya, 2012). El Oriente antioqueño era, entonces, un territorio rural, en donde el autoconsumo y la pequeña comercialización de productos eran las bases de la agricultura campesina que existía en la región (García y Aramburo, 2011).

Sin embargo, y según García y Aramburo (2011), esta dinámica comienza a cambiar aproximadamente en los años sesenta del siglo xx cuando el Oriente antioqueño pasa de ser una región sin importancia mercantil para las empresas y para el Estado Nacional, a diferencia de otras regiones de Antioquia en las que se realizaba explotaciones de oro como 
en el Norte y Bajo Cauca Antioqueños, a ser una región fundamental para el “desarrollo” del departamento y del país. Este cambio se basó en el aprovechamiento de los bienes naturales de la región para la generación de energía eléctrica, en el traslado de la industria del departamento a varios municipios de la región y en el desarrollo vial y aeroportuario del país que se consolidó en esta zona.

Esta nueva visión del Oriente antioqueño construida "desde arriba”" por las élites nacionales e internacionales fue propiciada, en parte, por las características ambientales, geográficas y territoriales de la región. La cantidad de afluentes hídricos, entre los que se encuentran los afluentes del río Magdalena y del río Cauca, como el río Nare, el río Samaná, el río Arma y el río Claro, su cercanía con el valle del Magdalena Medio y con los municipios de Puerto Triunfo y Puerto Nare, y las montañas de la Cordillera Occidental que atraviesan la región y que configuran un paisaje de grandes cañones y laderas (Iner, 2003), contribuyeron a que el oriente de Antioquia fuera visto como un territorio estratégico para el desarrollo de megaproyectos hidroeléctricos y para que allí efectivamente se construyeran las primeras grandes centrales hidroeléctri-

1 Con las expresiones lógicas y apropiaciones territoriales "desde arriba” y "desde abajo", no se quiere hacer alusión a una mirada neutra e imparcial ni tampoco excesivamente jerarquizada de los procesos sociales. Sí se quieren expresar las relaciones asimétricas y de poder en las dinámicas de apropiación del territorio, de manera que entendemos como lógicas "desde abajo", a aquellas apropiaciones que hacen grupos históricamente subalternizados por el capitalismo y la modernidad/colonialidad, indígenas y afrodescendientes, campesinos, pobladores de los territorios urbanos populares, jóvenes, mujeres, así como a las resistencias y movimientos sociales organizados, gestados y construidos por estos grupos. Con lógicas y apropiaciones territoriales "desde arriba" queremos hacer referencia a las apropiaciones hechas históricamente por grupos hegemónicos, Estado y empresas, que mediante el ejercicio del poder imponen violentamente lógicas específicas de organización de los territorios y de las poblaciones como forma de reproducir estructuras de acumulación de capital y de dominación. Lo que queremos enfatizar aquí es que la formación espacial e histórica es construida por una multiplicidad de tiempos y espacios imbricados atravesados por diversas relaciones de poder (Betancurt, 2015). 
cas del país en los años setenta y ochenta, respaldadas por el Estado y con el apoyo económico e ideológico del Banco Mundial² (Olaya, 2012).

De la misma manera, la cercanía con la región del Valle de Aburrá, región central del departamento de Antioquia en donde se encuentra localizada la ciudad de Medellín, propició que para la misma época se relocalizara allí, especialmente en los municipios de Rionegro, Marinilla, La Ceja, Santuario y Carmen de Viboral, gran parte del complejo industrial y agroindustrial de Antioquia que incluyó industrias de textiles, alimentos, bebidas, químicos, papel y vidrio, y ganadería de leche, porcicultura, avicultura y cultivos de flores para la exportación (Iner, 2003). Junto con este proceso de industrialización, y de la consecuente urbanización de los municipios del oriente de Antioquia más cercanos al Valle de Aburrá, la región fue el escenario de la consolidación de la infraestructura vial y de comunicaciones de Antioquia. Dada su cercanía al centro del departamento y dados sus límites con los departamentos Boyacá, Santander y Caldas, que conectan a Antioquia con el centro del país, se construyó el aeropuerto internacional de Antioquia en el municipio de Rionegro, la zona franca del Oriente antioqueño y la autopista Medellín-Bogotá, que conecta las dos ciudades más importantes del país.

Producto de esta forma de gestión y de organizar el territorio “desde arriba” fue creada, en 1984, la Corporación Ambiental de las Cuencas de los ríos Negro y Nare - Cornare-, con el objetivo de hacer inver-

2 Según Olaya (2012), y citando el estudio "El Sector Eléctrico Colombiano. Orígenes, evolución y retos. Un siglo de desarrollo [1882-1999]”, Interconexión eléctrica S.A. E.S.P. [s.1]. [s.e]. 2002, p.57, “En la construcción de estos grandes proyectos se dispuso toda la capacidad de endeudamiento del país con los organismos de financiamiento internacional. En el estudio se expresa que: 'entre 1970 y 1987, el Banco Mundial hizo quince préstamos a Colombia para proyectos de infraestructura eléctrica, por un valor cercano a los US\$1.900 millones, y el Banco Interamericano de Desarrollo contribuyó con una suma similar en préstamos', de manera que el total aportado por cada entidad representó cerca del $40 \%$ de los préstamos externos a largo plazo" (p. 68). 
siones y de administrar los recursos económicos de las transferencias, dinero que las empresas responsables por las centrales hidroeléctricas debían y deben dar a la región como compensación de los impactos socioambientales de estos megaproyectos. La creación de esta corporación respondió a los lineamientos que el Banco Mundial estableció en 1981 para el otorgamiento de créditos destinados a megaproyectos en América Latina ${ }^{3}$, y en su constitución los poderes regionales antioqueños se jugaron "el todo por el todo", ordenando y reinventando el territorio en coherencia con el discurso y la gestión del desarrollo del Oriente antioqueño (García y Aramburo, 2011). Así, Cornare organizó el territorio en cuatro subregiones: la subregión del Altiplano, (municipios de Rionegro, Guarne, Santuario, Marinilla, El Retiro, La Ceja, La Unión, San Vicente y Carmen de Viboral), zona con un fuerte proceso de industrialización y urbanización y en donde actualmente se encuentran grandes fincas de recreo; la subregión de Embalses (municipios de San Carlos, Alejandría, Guatapé, Concepción, San Rafael y el Peñol), en donde se dieron grandes transformaciones como producto de la construcción de embalses y donde decayó considerablemente la actividad agropecuaria campesina; la subregión de Páramo, (municipios de Argelia, Nariño, Sonsón y Abejorral), región con grandes riquezas naturales, ecosistemas de páramos y con un agricultura basada en la economía campesina; y la subregión Bosques (municipios de Granada, Cocorná, San Francisco y San Luis), también con un riqueza natural de importancia, ecosistemas de bosques tropicales, con actividades campesinas y con actividades sociales y económicas alrededor del eje vial de la autopista Medellín-Bogotá (Iner, 2003).

3 Según García y Aramburo (2011) la creación de Cornare como institución administradora de los recursos provenientes de los proyectos hidroeléctricos, respondió a las exigencias que hacia el Banco Mundial para otorgar créditos para megaproyectos en América Latina. La ley 56 de 1981, por la cual se dictan normas sobre obras públicas de generación eléctrica y acueductos, sistemas de regadío y otras, y se regulan las expropiaciones y servidumbres de los bienes afectados por tales obras respondería también a estas exigencias del Banco Mundial. 
Según García y Aramburo (2011), esta gestión y organización "desde arriba" del territorio del Oriente antioqueño ha generado que las construcciones territoriales estén enmarcadas en la fragmentación del territorio, en lo que muchos autores han llamado "el oriente cercano", que incluye principalmente los municipios de Rionegro y Marinilla, los cuales han sido escenario de un fuerte proceso de industrialización (así como también se han ubicado allí grandes fincas de recreo en donde políticos y empresarios del país han adquirido tierras) y "el oriente lejano y su periferia", la periferia del sur, con los municipios de la subregión de Paramos, y el oriente lejano, es decir, los municipios de la subregión de embalses más cercanos al río Magdalena.

\section{Figura 1. Mapa de localización del Oriente antioqueño}
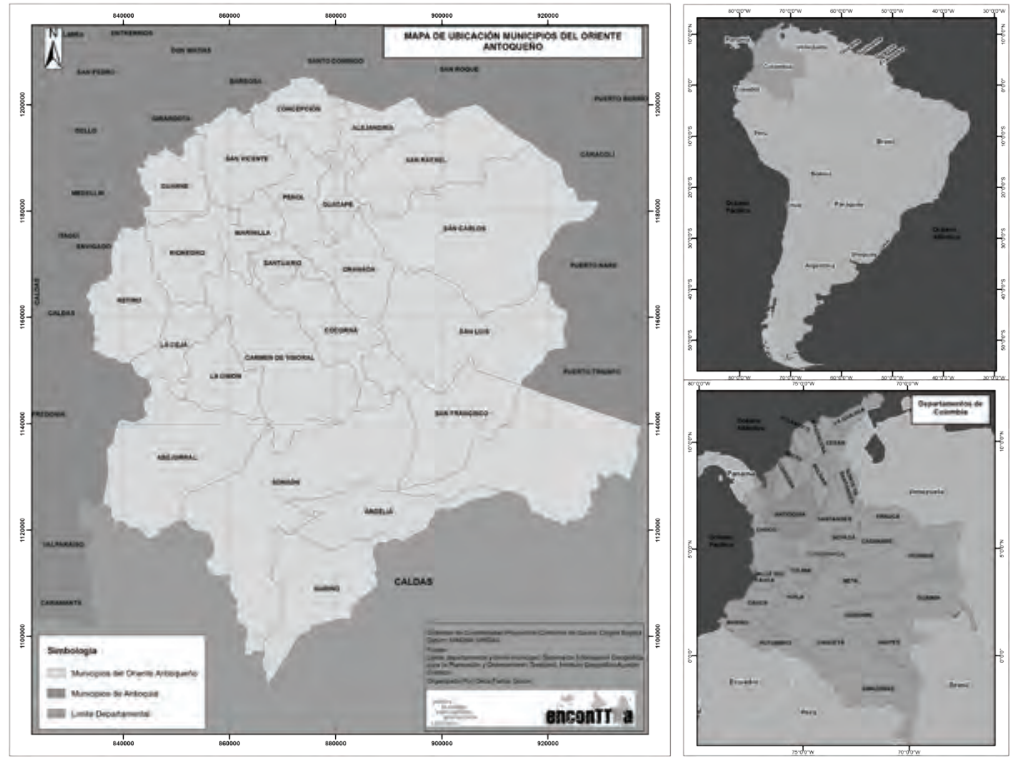

Fuente: limite departamental y límite municipal, sistema de información geográfica para la Planeación y Ordenamiento Territorial, Instituto Geográfico Agustín Codazzi.

Estos megaproyectos, hidroeléctricos, industriales y de vías, construidos en la segunda mitad del siglo $\mathrm{xx}$, transformaron completamente 
las dinámicas campesinas de la región del Oriente antioqueño. "Desde arriba” esta región comenzó a tener una importancia fundamental en el modelo de desarrollo que quería implantarse en el país, contando con todo el apoyo internacional y también con el apoyo de las élites y poderes nacionales y regionales. Sin embargo, y paralelamente, “desde abajo” el Oriente también comenzó a adquirir significados diferentes, enmarcados en los impactos que estos proyectos generaban en las formas locales, y construidos por los afectados y las afectadas por estos proyectos. Al experimentar fuertes cambios en las dinámicas territoriales, los pobladores campesinos del Oriente antioqueño comenzaron a movilizarse y a construir nuevos significados socioterritoriales basados en sus formas propias de relacionarse entre sí, con el territorio y con los bienes de la naturaleza.

La constitución de los movimientos cívicos ${ }^{4}$ en los años ochenta del siglo Xx es, ciertamente, una historia fundamental para los pobladores del Oriente antioqueño, que tiene significados profundos en las construcciones territoriales y organizativas, así como en las formas en las que ellas y ellos construyen relaciones con otros actores y con otras lógicas socioterritoriales. Estos movimientos en el Oriente tienen su eclosión como resultado de los impactos de la construcción de las grandes centrales hidroeléctricas en esta región, especialmente de la central

4 Los movimientos cívicos fueron movimientos sociales, no solo creados en el Oriente antioqueño, sino en gran parte del país en relación con diversas coyunturas nacionales, pero también con especificidades regionales y locales. Según García (2007), "su aparición y florecimiento en el contexto nacional se debía a la incidencia de factores estructurales como el desequilibrio regional, la concentración urbana, el deterioro del ingreso de las mayorías, la centralización del poder estatal, el constreñimiento político causado por la alternación bipartidista durante el Frente Nacional que, al tildar como subversivas las expresiones de oposición y las acciones reivindicativas, ocluyó los canales de expresión de demandas sociales y de negociación con el Estado" (p.92). En relación con el nombre de movimientos cívicos, "el adjetivo cívico fue acuñado por los participantes en estas luchas con la pretensión de legitimarlas frente a los poderes estatales - que las tildaban de subversivas-, de sustraerlas de la acción de los partidos políticos y de la guerrilla, y de mostrarlas ajenas a una clase social específica, destacando el carácter general y legítimo de sus exigencias” (pp.89-90). 
hidroeléctrica Guatapé, con el embalse del Peñol (municipios de Guatapé y el Peñol, 1972), la central hidroeléctrica y el embalse de Playas (municipio de San Rafael, 1979), la central hidroeléctrica de San Carlos, con el embalse Punchiná (municipio de San Carlos, 1984), la central hidroeléctrica Jaguas, con el embalse San Lorenzo (municipios de Alejandría y San Rafael, 1988), y la pequeña central hidroeléctrica Calderas (municipios de San Carlos y Granada, 1988).

De hecho, en la época de construcción de la central hidroeléctrica Guatapé y del embalse del Peñol se generaron fuertes movimientos cívicos en los dos municipios afectados, Guatapé y El Peñol, consolidados por pobladores que protestaban por la inundación y el despojo de sus tierras, por la pérdida de tierras dedicadas a la agricultura, por la pérdida de sus trabajos y labores campesinas y por la pérdida de valores y prácticas culturales que generaban en los pobladores sentimientos generalizados de desorientación y desarraigo (Sáenz, 1986). Sin embargo, no solo fueron los impactos directos de la construcción de estas obras lo que terminó por difundir y ampliar los movimientos cívicos a todo el Oriente antioqueño, sino también el alza en los precios de la energía eléctrica ${ }^{5}$, aspecto que desencadenó una fuerte movilización en toda la región y que generó el crecimiento del sentimiento de injusticia y de imposición de proyectos "desde afuera" en las comunidades campesinas.

Tanto con acciones jurídicas y administrativas, como con diálogos y acciones de hecho, los movimientos cívicos en el Oriente antioqueño construyeron una memoria colectiva basada en la injusta política

5 Según Olaya (2012), en 1982 la electrificadora de Antioquia envió una circular comunicando el alza general en las tarifas de energía en los municipios del Oriente antioqueño, incluyendo los que eran afectados por la construcción de las hidroeléctricas, aumentando el malestar en los pobladores que ya vivían los impactos socioambientales de estas construcciones, y desencadenando así la articulación de las organizaciones y la unión de los movimientos cívicos en el Oriente. De la misma manera, García (2007) afirma que el alza en las tarifas de energía eléctrica en el marco de la política nacional de las tarifas de energía fue la "chispa y el motor" de los movimientos cívicos en la zona. 
energética del Estado, en la imposición de proyectos sin consulta alguna a las comunidades, en los enormes prejuicios que estos proyectos generaron en las relaciones sociales, territoriales y ambientales de las poblaciones campesinas y en las pocas, ineficientes o nulas compensaciones y beneficios recibidos por la instalación de estos megaproyectos en la región (García y Aramburo, 2011). En el contexto de la consolidación de estos movimientos cívicos, se realizaron allí tres paros cívicos (1982-1984) en los que se articularon exigencias, se establecieron diálogos con el Estado nacional y regional y se originó una amplia difusión de las problemáticas. Durante los cuatro años de movilizaciones sociales, se construyeron procesos formativos y organizativos que dejaron una honda huella en la memoria colectiva, cultivando en los pobladores del Oriente antioqueño un sentido de pertenencia territorial basado en la capacidad de organizarse, de unirse y de enfrentar y reivindicar derechos, formas de vida y relaciones sociales y territoriales propias, pero también basado en un sentimiento de descontento en relación con los discursos y prácticas de los gobernantes, élites y poderes nacionales y regionales que imponen injusticias, violencias y que ignoran sus reivindicaciones y derechos (Olaya, 2012).

Sin embargo, estos cambios territoriales drásticos no solo fomentaron la construcción de visiones del territorio construidas “desde arriba” y “desde abajo”, como se señaló anteriormente, sino también la inmersión de la región del Oriente antioqueño dentro de las dinámicas y lógicas del conflicto armado del país. Con la llegada, primero, de las guerrillas de las FARC y el ELN en los años ochenta y, años después, de grupos de extrema derecha y del grupo Muerte a Secuestradores - MAS - (Olaya, 2012), se configura un escenario de guerra que termina acabando de manera totalmente violenta con los movimientos cívicos de esta zona a finales de la década de los años ochenta. Mediante asesinatos sistemáticos a líderes sociales, comienza una época de terror entre 1985 y 1987, que desplaza a muchos de los pobladores de la región y que desarticula las organizaciones sociales, las reivindicaciones y las luchas en el Oriente antioqueño (Olaya, 2012). 
A pesar de lo anterior, en los años noventa, las organizaciones sociales vuelven a activarse en la región. Con la Constitución de 1991, en la que se declara, entre otras cosas, a Colombia como un país descentralizado y se abre la posibilidad de acción, de autonomía y de manejo de recursos por parte de las instituciones locales y municipales y por parte de las comunidades organizadas, se activan nuevas formas de organización social que promueven la participación comunitaria en la planeación y en la asignación de recursos en todo el país, y en el Oriente antioqueño, especialmente, se abre la posibilidad de la participación comunitaria en el manejo de los recursos económicos venidos de las transferencias que otorgan las empresas que hacen parte de sector eléctrico ${ }^{6}$.

El movimiento Oriente Unido es una muestra importante de lo anterior. Con el apoyo de las administraciones municipales, varias asociaciones emprendieron diversos proyectos de participación comunitaria con el objetivo de rehacerse y de recuperar los territorios de las dificultades económicas y sociales que la construcción de estos megaproyectos y la violencia habían generado en la región. Sin embargo, a finales de la década en mención, una nueva escalada de violencia y de guerra llega al Oriente antioqueño, desarticulando la organización comunitaria y afectando de forma severa los tejidos sociales y territoriales de los pobladores. Se trató entonces, de 1997 al 2005, de una verdadera crisis humanitaria en la región?

6 Según Olaya (2012) desde 1983 el porcentaje económico que las empresas del sector eléctrico responsables por las centrales hidroeléctricas debían dar como transferencias a las regiones en donde se encontraban era del $4 \%$, recurso económico que era administrado por la Corporación Ambiental de las Cuencas de los ríos Negro y Nare - Cornare-. Sin embargo, después de la Ley General Ambiental de Colombia (Ley 99 de 1993), y en el marco de la nueva Constitución Política de Colombia de 1991, este porcentaje subió del $4 \%$ al $6 \%$ y se dividió la administración de estos recursos, de manera que el $3 \%$ eran gestionados por Cornare y el otro $3 \%$ por los municipios. Así, se abrió la posibilidad de que los municipios -y, por lo tanto, los habitantes organizados - pudieran intervenir por primera vez en la administración de estos recursos económicos.

7 Según García y Aramburo (2011) existió un antes y un después de 1997 en la historia y en la geografía del conflicto armado en el Oriente antioqueño y en muchas 
Sin embargo, cuando las lógicas y estructuras del terror, la violencia y la guerra se instalaban en el día a día de los pobladores y de las comunidades, cuando parecía que los sentidos de la Existencia desaparecían y cuando las poblaciones eran humilladas, destruidas y despojadas de sus territorios y del poder de articular exigencias (García y Aramburo, 2011), en ese mismo momento resurgen, se recrean y se reconstruyen tejidos sociales y territoriales y r-Existencias ${ }^{8}$ (Porto-Gonçalves, 2015) en el Oriente antioqueño, esta vez enmarcados en disminuir los efectos más devastadores de la guerra, en buscar y construir herramientas para superar el miedo y el terror y en encontrar soluciones conjuntas al conflicto armado. Con movilizaciones, marchas, caravanas, concentraciones, jornadas de silencio y diálogos con instituciones estatales, empresas y actores armados, surgen en el Oriente antioqueño asambleas

partes del país, debido a que en este período los diversos grupos paramilitares se unificaron en las Autodefensas Unidas de Colombia - AUC- bajo el mando de Carlos Castaño, unión que tuvo efectos fundamentales en las dinámicas de la guerra que se vivían hasta ese momento. En efecto, en 1997, el fenómeno paramilitar se extiende, unifica y fortalece, llegando al Oriente antioqueño y consolidando su poder en la región. Mediante su estrategia de guerra contrainsurgente, las AUC, y especialmente el Bloque Metro y las Autodefensas Unidas del Magdalena Medio, copan los espacios donde transitan las guerrillas, llegando con "listados de la muerte" y con informaciones de líderes y proyectos comunitarios, buscando mediante masacres, asesinatos y desapariciones forzadas acabar con la supuesta base social de las guerrillas. Así, con una estrategia de terror que se extiende hasta aproximadamente el 2005, año en que las AUC se desmovilizan formalmente, los paramilitares, con el apoyo del ejército y la policía, rompen los tejidos organizativos y comunitarios, acaban con procesos de participación y planeación comunitaria, expropian y despojan a los campesinos y generan violentos procesos de desplazamientos forzados colectivos en la región.

8 Utilizamos la palabra $r$-Existencia haciendo alusión al planteamiento de Porto Gonçalves (2006), según el cual no solo se resiste desde la movilización social organizada, sino también a partir de la existencia, de lo que ya existe y se ha construido espacial y temporalmente, "lo que se tiene es r-Existencia puesto que no se reacciona, simplemente a la acción externa, pero, si, que algo pre-existe y es a partir de esa existencia que se R-Existe. Existo, luego, resisto. R-Existo" (PortoGonçalves, 2006, p.47). Entendemos, por lo tanto, la r-Existencia como todas aquellas formas de resistencia que tienen como base la permanencia y reproducción de modos de vida, de sistemas socioculturales, de relaciones de producción-sustentabilidad de la vida y de relaciones territoriales, espaciales y con la naturaleza: de todo lo que significa el existir. 
comunitarias, redes de jóvenes, redes de juntas de acción comunal, asociaciones de mujeres y otras organizaciones en busca de encontrar una salida al conflicto armado mediante el diálogo y de superar el miedo, construyendo colectivamente nuevos sentidos y Existencias ${ }^{9}$. La Asociación de Mujeres del Oriente antioqueño - Amor-, el Consejo de Conciliación de San Luis y la Asociación provincial de Victimas a Ciudadanas -Aproviaci- son muestran de lo anterior ${ }^{10}$.

9 A partir de la comprensión de la r-Existencia, en diversas partes del texto utilizamos la palabra Existencia en mayúscula, entendiéndola como un como un existir, como un estar puesto, como un ser ahí, un ser en el mundo, proyectado en el mundo, un ser en una geografía y en una historia (Martins, 2007). Desde esta perspectiva, la Existencia representa la estructura de relaciones que un ser-colectividad establece con el mundo y con los otros, la fuerza de la relación entre geografía e historia. Cuando escribimos la palabra Existencia con mayúscula en el texto nos estamos refiriendo a todas las formas cotidianas de vivir, a todas las formas por medio de las que nos remitimos a la vida, a todas las formas de aprehensión, apropiación, comprensión, interpretación del espacio y del tiempo que solo por el hecho de permanecer y de sobrevivir se convierten en formas de resistir al poder, en formas de r-Existencia.

10 La creación de estas organizaciones se originó en un contexto de guerra y violencia en la que los pobladores del oriente, las asambleas comunitarias, los párrocos de las iglesias, las ONG y los alcaldes electos en los municipios comienzan a articularse y a movilizarse con el objetivo de resistir a los embates de la guerra, de reparar tejidos sociales, culturales, territoriales y políticos, y de buscar soluciones y diálogos al conflicto armado. Fruto de estas articulaciones, las asambleas comunitarias y los alcaldes de los municipios logran establecer diálogos con algunos actores armados, especialmente con el ELN y con algunos comandantes de las AUC. Como consecuencia de esto, además de los impactos de las movilizaciones, comienzan a juntarse al movimiento otros actores institucionales y privados como la Gobernación de Antioquia y Prodepaz, (institución que aglutina empresas del sector eléctrico nacional como ISA e Isagén), y con ayuda de recursos de la Unión Europea se pone en marcha el "laboratorio de paz", que coincide con la Política de Seguridad Democrática y con la desmovilización paramilitar. Producto de la puesta en marcha de este laboratorio y de la coincidencia con estas políticas, se han establecido diversos debates en relación con la despolitización de los movimientos sociales y con la fragmentación de las luchas que genera la intervención de las instituciones públicas nacionales y departamentales y de los organismos internacionales. (García y Aramburo, 2011). Existe también un debate en relación con la legitimidad o la ilegitimidad de la desmovilización paramilitar y sobre el papel que las víctimas deben asumir frente a los procesos de reparación y verdad; hay diversas perspectivas relacionadas con la reconciliación y con el modelo de reconciliación víctimas-victimarios. Muchas organizaciones de víctimas aceptan la conciliación en una relación local activa con 
Podemos señalar, a partir de lo anterior, que el territorio del Oriente antioqueño ha sido construido por una diversidad de lógicas, actores y estructuras que se "enredan complejamente" (Grosfoguel, 2008) y que entran en relación, en contradicción y en conflicto. Por un lado, la región es concebida como un territorio perfecto para la extracción y explotación de bienes de la naturaleza y para la construcción y consolidación de grandes megaproyectos; por otro lado, el Oriente antioqueño es construido a partir de una diversidad de significados socioterritoriales confeccionados por comunidades y colectividades que piden justicia ambiental y social, reconocimiento de sus valores y prácticas culturales, participación real y efectiva y autonomía para desarrollar proyectos sociales y comunitarios; y, finalmente, el Oriente antioqueño también es construido por una diversidad de actores armados que se entrelazan complejamente con los métodos del extractivismo y de la resistencia y que también imprimen e influencian con sus propias lógicas y prácticas estas diversas formas de erigir territorio en el Oriente antioqueño.

\section{Conflictos socioambientales actuales y modelo neoextractivista en el oriente del departamento de Antioquia}

La diversidad mediante la cual se ha construido el territorio del Oriente antioqueño es parte fundamental de la formación histórica y espacial actual, así como de los conflictos socioambientales que en el presente se configuran en la región. Después de la desmovilización paramilitar en el año 2005 y de la paralela consolidación de la presencia del ejército y la policía nacional, así como de la disminución del accionar de

los desmovilizados, mientras que otros movimientos y organizaciones tienen una posición crítica completa y en todo nivel de la concepción y aplicación de la Ley 975 de 2005, Ley de Justicia y Paz, y creen firmemente que la desmovilización fue un proceso ambiguo y que aún es un horizonte por construir en Colombia. Por estas razones, la organización, los efectos y las políticas del "laboratorio de paz" en Antioquia son objeto de un amplio debate y discusión en el Oriente antioqueño. 
las guerrillas ${ }^{11}$, se relanza la estrategia extractivista (frenada en parte por el conflicto armado), basada en la promoción y consolidación de la megaminería transnacional y de las grandes, pequeñas y microcentrales hidroeléctricas.

En efecto, y aproximadamente desde el año 2007, hay un resurgimiento de los intereses extractivistas en el Oriente antioqueño, con un aumento de los títulos y de las solicitudes para explotación de minerales, oro, metales preciosos y materiales para la construcción, y con un incremento de las solicitudes, estudios y construcciones de grandes, pequeñas y microcentrales hidroeléctricas. Estos megaproyectos se encuentran planeados para gran parte del oriente de Antioquia, pero principalmente para los municipios de San Carlos, San Luis, Cocorná, Nariño, Sonsón, Argelia, Abejorral, San Francisco, Alejandría, La Unión y Carmen de Viboral.

Existen aproximadamente 170 títulos para la explotación minera, 274 solicitudes para nuevos títulos mineros y tres zonas de minería especial en la región del oriente de Antioquia ${ }^{12}$, lo que configura un escenario

11 Paralelamente a los años de consolidación del paramilitarismo en el Oriente antioqueño y a la crisis humanitaria que vivió esta región de 1997 hasta el año 2005, se consolida también la presencia del Ejército Nacional y de la policía. De hecho, a comienzos de los años noventa, y cuando las guerrillas logran un avance considerable en la región, son frenadas por el accionar conjunto de los paramilitares y del Ejército Nacional, en una estrategia que se basó en la captura paramilitar de los espacios que iba liberando la fuerza pública (Observatorio de Paz y Reconciliación del Oriente antioqueño, 2007). Así, se da un relevo entre paramilitares y las fuerzas armadas del Estado, y en el marco de varias ofensivas militares efectuadas dentro de la política de seguridad democrática (que comienza a consolidarse desde 2002), las fuerzas armadas del Estado recuperan los territorios que habían tomado las guerrillas, consolidando su accionar y su presencia aproximadamente en 2005 (García y Aramburo, 2011). Con la desmovilización paramilitar efectuada en el mismo año, las fuerzas armadas del Estado recuperan el dominio militar del Oriente antioqueño, control que tienen actualmente.

12 En relación con las zonas de minería especial, la Ley 1450 del 6 de junio de 2011, por la cual se adopta el Plan de Desarrollo Nacional 2010-2014, establece su creación, afirmando que son regiones destinadas a la actividad minera, pero en las cua- 
futuro de explotación minera intensiva en este territorio. Efectivamente, los títulos ya se encuentran otorgados, la mayoría sobre la figura de contrato de concesión que garantiza la explotación por entre veinte a treinta años, pero las acciones de explotación directa del material de la mayoría de los títulos, especialmente los de oro y metales precisos, aún no han comenzado y tampoco cuentan con licencia ambiental.

La explotación minera se concentra actualmente en las minas de materiales para la construcción de Río Claro, realizada por la empresa Argos entre los municipios de San Carlos, San Luis y Puerto Nare; en las minas del municipio de La Unión, llevada a cabo por la misma multinacional; y en las minas de materiales para la construcción de Rionegro y Guarne, llevadas a cabo por la Empresa Nacional Constructora y Clasificadora de Materiales para la Construcción Ltda. Las empresas que tienen estos títulos de extracción de materiales para la construcción son principalmente multinacionales con capitales extranjeros, dentro de las cuales se encuentran Cementos Argos de Colombia ${ }^{13}$, Cemex de México y Holcim de Suiza, y para la minería de oro y de metales precisos, las multinacionales Anglo Gold Ashanti de Suráfrica y Northern Colombia de Canadá.

Es importante señalar que, si bien existen títulos que aparecen inicialmente a nombre de otras empresas, como aquellos de las empresas nacionales T.E.S.S.A, Suministros de Colombia S.A., Negocios Mineros s.A., Cementos Río Claro s.A. e Ingetierras de Colombia, según el Catastro Minero Colombiano, registro oficial del Ministerio de Minas y

les no se realizan actividades en la actualidad, sino que se proyectan para futuras intervenciones (Corporación Jurídica Libertad, 2015).

13 La empresa Cementos Argos nace en Antioquia en 1934. A finales de los años noventa, la empresa realiza alianzas para adquirir cementeras en Panamá, Haití y República Dominicana, y en 2003 se fusionan a esta empresa varias cementeras colombianas. En 2005 son adquiridas por esta empresa dos empresas de concreto norteamericanas, ampliando su influencia considerablemente y consolidándose actualmente como la cuarta productora de concreto de Estados Unidos. 
Energía, en estos títulos también aparecen implicadas las mismas cinco multinacionales mencionadas anteriormente. Además de lo anterior, si bien Argos, Holcim y Cemex aparecen primordialmente en títulos de explotación de materiales para la construcción, y Anglo Gold Ashanti y Northern Colombia en títulos para la explotación de oro y metales preciosos, existen títulos en los que estas últimas aparecen en la explotación de materiales para la construcción, así como algunos en los que Holcim, Cemex y Argos aparecen en la explotación de oro y metales preciosos.

En relación con la generación de energía eléctrica, existen aproximadamente sesenta grandes, pequeñas y microcentrales hidroeléctricas ${ }^{14}$, bien sea en estudio, en construcción o activas y que generan energía eléctrica en la subregión del oriente de Antioquia. Existe especialmente un auge por las pequeñas centrales hidroeléctricas, que generan un estimado de $10000 \mathrm{~kW}$ o menos y construidas a filo de agua y sin embalse, incremento auspiciado por el Estado Nacional por medio del Decreto 2820 de 2010, en el cual se establece que las empresas no tienen que pagar transferencias para estas construcciones y que no necesitan solicitar licencia ambiental, es decir, que no necesitan de un estudio de impacto ambiental -EIA - y que los permisos son otorgados bajo la figura de concesión de aguas. De esta manera, no solo los principales ríos del Oriente antioqueño se encuentran ya intervenidos por estas construcciones, como el río Cocorná con la PCH El Popal, el río Guatapé con las

14 Según el atlas hidroeléctrico, las hidroeléctricas en Colombia se clasifican en cinco tipos: las picocentrales, con capacidad instalada entre 0,5 y $5 \mathrm{~kW}$, con operación a filo de agua y aplicables a zonas no interconectadas o casos aislados de zonas interconectadas; las microcentrales, con capacidad instalada entre 5 y $50 \mathrm{~kW}$, con operación a filo de agua y aplicables a zonas no interconectadas o casos aislados de zonas interconectadas; las minicentrales con capacidad instalada entre 50 y $500 \mathrm{~kW}$, con operación a filo de agua y aplicables a zonas no interconectadas o casos aislados de zonas interconectadas; las pequeñas centrales hidroeléctricas - $\mathrm{PCH}$ - , con capacidad instalada entre 500 y $20000 \mathrm{~kW}$, operación a filo de agua y aplicables a zonas no interconectadas y zonas interconectadas; y las centrales hidroeléctricas, con capacidad mayor a $20000 \mathrm{~kW}$, con embalse y aplicables a zonas interconectadas (UPME, 2015, p.28). 
centrales hidroeléctricas San Carlos, Playas y Guatapé, el río Calderas con la $\mathrm{PCH}$ Calderas y el río Nare con la central hidroeléctrica de Jaguas, sino que también han sido intervenidos, con el auge de las micro y pequeñas centrales hidroeléctricas, pequeños afluentes, quebradas y cascadas, como el río Santo Domingo, la quebrada de Granada, el río La Paloma, la quebrada de Alejandría, el río Melcocho, entre otros.

La dinámica de las empresas en la construcción de estos proyectos de generación de energía es diferente a la de las empresas involucradas en la explotación minera. Comúnmente, en las distintas fases de construcción de hidroeléctricas intervienen diversas empresas, actuando una en la etapa de estudios de factibilidad, otra en la construcción y otra en la etapa de generación y mantenimiento, aunque generalmente existe una empresa responsable por el proyecto en su totalidad. Es de resaltar también el papel de las alianzas entre empresas, que pueden ser tanto de capitales extranjeros con capitales nacionales como público-privadas, entre empresas nacionales y diversas instituciones públicas y estatales de fomento a estos proyectos. Generalmente, a partir de estas alianzas, se crean y se constituyen nuevas empresas y figuras jurídicas para cada proyecto específico, como es el caso de la sociedad PCH Alfaguara S.A. para la construcción de la minicentral Entre Aguas, de la sociedad Hidroeléctrica Río Aures S.A. para la construcción de la Central hidroeléctrica sobre el río Aures, de la sociedad Generadora de Alejandría s.A. E.S.P., para la construcción de la PCH Alejandría, entre otras.

Dentro de esta dinámica, las principales compañías que intervienen son las Empresas Públicas de Medellín —EPM, la única empresa pública que aún interviene en estos proyectos y que está encargada de las centrales hidroeléctricas de Guatapé y Playas y de las minicentrales Sonsón I y Sonsón II-, la empresa Isagén — privatizada recientemente y encargada de la centrales hidroeléctricas de Jaguas, San Carlos y de la PCH Calderas-, la empresa Emgea - producto de una alianza públicoprivada en la que participan la Gobernación de Antioquia, el Instituto de Desarrollo de Antioquia (Idea), la Cámara Colombiana de Infraes- 
tructura y la Sociedad Antioqueña de Ingenieros y Arquitectos (SAI)-, la Fundación Promotora del Empleo en Antioquia - que es propietaria de cuatro proyectos de minicentrales en el río La Paloma, de la PCH Alejandría sobre el río Nare y de dos proyectos de minicentrales en el río Sirgua-, la empresa Celsia — que hace parte de Argos y que lidera los proyectos de centrales hidroeléctricas Porvenir I y Porvenir II-, la empresa Helm Group Company HBI Banca de Inversión —con la PCH El Popal, la central hidroeléctrica San Miguel y las PCH El Molino y San Matías, que construye en conjunto con la empresa HMV Ingenieros- y Generamos Energía S.A. - con el proyecto de construcción de la minicentral sobre el río Dormilón-.

Este modelo y esta visión del modelo neoextractivo configurada "desde arriba”, auspiciado por las instituciones globales y nacionales, y en el marco de una aparente estabilidad lograda después de la época crítica del conflicto armado, ha propiciado nuevamente la desapropiación, el despojo y las transformaciones en las lógicas socioterritoriales y en los tejidos culturales de las comunidades campesinas del Oriente antioqueño. Después de los numerosos desplazamientos forzados que estas comunidades han experimentado, lo cuales han ocurrido históricamente por causa de la construcción de proyectos hidroeléctricos en los años ochenta y por la violencia sistemática contra organizaciones y movimientos sociales y comunitarios, las poblaciones campesinas de esta zona comienzan una época de retorno a sus territorios a partir del año 2005 con la desmovilización paramilitar. Sin embargo, actualmente las comunidades no solo tienen que hacer frente al miedo del retorno, sino también a los nuevos desalojos y a las transformaciones violentas que impone este resurgimiento y auge del modelo extractivo en la región. "Primero nos quitan los seres queridos y ahora el territorio" 15 , "La misma cosa que un desplazamiento, a la buena o a la mala, es como los

15 Entrevista realizada a Flor Gallego, participante del Movimiento por la Defensa de la Vida y del Territorio - Movete- en marzo de 2016. 
grupos armados”, "Ahora la empresa nos va a volver a sacar”16, son las voces de algunos habitantes del Oriente antioqueño.

Es por lo anterior que en esta región actualmente no solo resurgen los intereses extractivistas, sino también nuevas formas de r-Existencias y de movimientos sociales y organizaciones comunitarias, que se oponen nuevamente a estas intervenciones y a esta construcción territorial “desde arriba” y sin la gente, que parten de la memoria colectiva, de los procesos formadores organizativos y de su "estoque” de prácticas y experiencias que han construido en estos territorios y frente al Estado y las empresas (Menezes y Malagodi, 2015). "El territorio es diseñado desde arriba, los campesinos no queremos eso"17.

Dentro de estas nuevas formas de organización y de r-Existencias, encontramos el:

movimiento social por la vida y la defensa del territorio del Oriente de Antioquia Movete, el cual agrupa a organizaciones sociales, culturales, ambientalistas, defensoras de derechos humanos, organizaciones comunitarias, entidades y personas que estamos por la defensa de la vida, el territorio y la paz (Olaya, 2015, p.16).

Movete agrupa organizaciones principalmente de once municipios del Oriente antioqueño dentro de las que se encuentran la Asociación Campesina de Antioquia - ACA-, la Asociación de Mujeres de Antioquia -Amor-, la Red de Acción Frente al Extractivismo, la Tulpa Juvenil, el Movimiento Vigías del Río Dormilón, la Asociación de Productores

16 Relato que se encuentra en el documental Represando el Porvenir, de la serie documental Memoria y Territorio, realizado por la Escuela de Creación DocumentalÁrea de Comunicaciones de la Asociación Campesina de Antioquia ACA. Producciones El Retorno, 2014.

17 Entrevista realizada a Ancísar Morales, miembro del Movimiento por la Defensa de la Vida y del Territorio -Movete- y de la Asociación Campesina de Antioquia ACA, en abril de 2016. 
del Oriente antioqueño - Asoproa-, entre otras organizaciones y personas, junto también con tres ONG: la Corporación Jurídica Libertad, Conciudadania y la Corporación de Estudios y Educación Ambiental -Ceam-. Las organizaciones del Movete se han posicionado contra este resurgimiento del modelo extractivo, denunciando los consecuentes impactos socioambientales, las recurrentes violaciones a los derechos humanos y realizando diversas acciones para frenar los proyectos que ilustraremos a continuación.

\section{Casos específicos de conflictos socioambientales actuales en el Oriente antioqueño}

Uno de los conflictos más significativos que existen actualmente tiene que ver con la construcción de micro, mini y pequeñas centrales hidroeléctricas. A partir del 2010, y dadas las condiciones favorables para este tipo de emprendimientos, la autoridad ambiental - Cornarecomienza a otorgar concesiones a particulares para la construcción de estos proyectos. La capacidad instalada de estas construcciones es de 5 a $50 \mathrm{~kW}$ para las micro, de 50 a $500 \mathrm{~kW}$ para las mini y de 500 a $20000 \mathrm{~kW}$ para las pequeñas centrales hidroeléctricas, las cuales se construyen a filo de agua, es decir que no necesitan de embalse para su funcionamiento ${ }^{18}$. En el discurso empresarial y estatal, que sean micro y pequeñas centrales hidroeléctricas garantiza que el impacto social y

18 Según el atlas hidroeléctrico (UPME, 2015), las centrales a filo de agua "se construyen en los lugares en que la energía hidráulica debe emplearse en el instante en que se dispone de ella, para accionar las turbinas hidráulicas. No cuentan con reserva de agua, oscilando el caudal suministrado según las estaciones del año” (p.27). Este tipo de construcción es diferente de las centrales con embalse en las que "se embalsa un volumen considerable de agua mediante la construcción de una o más presas que forman lagos artificiales; el embalse permite regular la cantidad de agua que pasa por las turbinas, con el fin de unificar las variaciones temporales de los caudales afluentes en el río. Las centrales con almacenamiento o regulación exigen, por lo general, una inversión de capital mayor que las de filo de agua, pero facilitan el incremento de la producción energética, disminuyendo el costo de la energía generada" (p.27). 
ambiental sea menor, y bajo este lema se sustentan la mayoría de los proyectos.

Sin embargo, para el Movete, si bien los impactos de estas construcciones pueden ser diferentes a los producidos por las grandes centrales hidroeléctricas, no son necesariamente menores ni menos importantes. Este punto lo demuestran las distintas luchas emprendidas contra estos proyectos y contra los discursos y prácticas, tanto de las empresas como de la Cornare, que han organizado y llevado a cabo varias organizaciones que pertenecen al Movete, y dentro de las cuales se encuentran las pugnas contra las microcentrales La Chorrera, El Río Dormilón, HidroArma, San Miguel y El Popal. Las disputas y defensas por el territorio alrededor de la microcentral La Chorrera y de la PCH El Río Dormilón son de especial interés, ya que estos dos proyectos fueron cancelados y sus concesiones y licencias ambientales revocadas por las acciones, prácticas y discursos, principalmente, de dos organizaciones que hacen parte del Movete: el movimiento Vigías del Río Dormilón, en el municipio de San Luis, y la organización Natyvos, en el municipio de San Carlos.

En San Luis existe una cultura del agua, donde se construyen estrechas relaciones económicas, sociales y recreativas con el río, una cultura en donde la cotidianidad y las historias de vida de los pobladores se entrelazan con el recorrido y la historia del río, y en donde los significados místicos y espirituales surgen y se construyen en torno a esta fuente de agua. Por todos estos significados, los habitantes comenzaron un proceso de consulta, reivindicación y lucha contra la construcción de una PCH en el río Dormilón, proyecto de la empresa Generamos Energía S.A. y que tenía previsto generar 6,9 MW de energía. La oposición fuerte comienza en el 2012, cuando las organizaciones de San Luis deciden realizar una asamblea comunitaria y elevar varios derechos de petición, por medio de los cuales van acumulando más conocimientos y ganando profundidad en sus discusiones con Cornare y con la alcaldía del municipio, hasta llegar al punto de oponerse rotundamente al acto ad- 
ministrativo que concesionaba las aguas del río Dormilón y de asumir la construcción de este proyecto como un "acto de profundo engaño, injusticia e inequidad hacia los sanluisianos" ${ }^{19}$.

Basados en un lenguaje con enfoque de soberanía popular, por medio del cual se exige que las decisiones que se tomen sean consultadas con el pueblo, y con enfoque en los derechos humanos, por medio del cual exigen que se respeten "los derechos de la gente para con su río", el movimiento Vigías de Río Dormilón declara la ilegitimidad del proyecto, debido al nivel de sincretismo de las acciones y debido a los fuertes impactos socioambientales que incluyen la perdida de balnearios, de valores paisajísticos, de aguas que se utilizan para la pesca, de opciones económicas basadas en la extracción de materiales que arrastra el río, de caminos tradicionales que dan acceso al río y el aumento de la contaminación y de los impactos de otras obras complementarias como carreteras e infraestructuras. Todo esto llevó a que se estableciera una mesa de diálogo con Cornare - se realizaron cinco reuniones en seis meses - y que finalmente, gracias a la presión del movimiento - que incluyó una marcha por la autopista Medellín-Bogotá apoyada por todas las organizaciones del Movete-, Cornare emitiera la declaración de caducidad de la concesión de aguas que permitía el uso del río Dormilón para la generación de energía eléctrica.

Por su parte, la quebrada La Chorrera de Puerto Rico es un afluente localizado en las cercanías del casco urbano del municipio de San Carlos y, al igual que el río Dormilón, es un referente cultural fundamental para los habitantes, consolidándose como parte del "patrimonio na-

19 Testimonio de los habitantes de San Luis, que se encuentra registrado en la sistematización que el movimiento Vigías del Río Dormilón construyó de su proceso de lucha y reivindicación. El documento Sistematización del proceso ciudadano por la protección y defensa del río Dormilón fue facilitado por la organización en mención durante el trabajo de campo en abril de 2016, pero aún no ha sido publicado oficialmente. 
tural y paisajístico del pueblo”20. Por esto, cuando un particular llegó comprando los terrenos aledaños y tiempo después se enteraron del plan de construir allí una microcentral, la mayoría de los pobladores se opuso: "es un paisaje muy bonito lleno de selva. Toda la vida los habitantes hemos visto la quebrada y hemos disfrutado de esta"21; "se entregará a una sola persona el aprovechamiento del recurso de agua. Un recurso que es público y propietario para el consumo humano. Dañará el paisaje de manera irreparable”22.

De esta manera los pobladores, con el apoyo de la personera y de la alcaldesa del municipio, además de la organización Natybos Naturaleza y Bosque, presentaron una solicitud para la realización de una audiencia pública ambiental con el fin de discutir el proyecto que planeaba la construcción de una microcentral con capacidad de 1.6 MW a filo de agua por parte de la empresa PCH La Chorrera, a nombre de Eliberto Ramírez. En esta audiencia ambiental, organizada por Cornare en el municipio de Guatapé, la comunidad presentó diversos argumentos contra este proyecto, dentro de los que se encuentran la afectación a los acueductos veredales por la reducción del caudal del agua, la contradicción con el Plan de Ordenamiento Territorial del municipio y con las determinaciones del consejo municipal, que declaran esta zona como de protección ambiental, y la afectación al turismo y especialmente al Plan de Desarrollo Turístico Sostenible y Comunitario estructurado en el marco del proyecto “Turismo Para la Paz" — creado en el segundo laboratorio para la paz del Oriente antioqueño- como alternativa so-

20 Relato obtenido de la noticia "La micro central hidroeléctrica La Chorrera (PCH) municipio de San Carlos” publicada el 22 de abril de 2014 por Dubier Felipe Herrera. Recuperado de http://micrlchorrera.blogspot.com.br/2014/04/la-microcentralHidroeléctrica-la.html

21 Entrevista realizada a miembro del Movete en marzo de 2016, durante el trabajo de campo.

22 Relato obtenido de la noticia "La micro central hidroeléctrica La Chorrera (PCH) municipio de San Carlos” publicada el 22 de abril de 2014 por Dubier Felipe Herrera. Recuperado de http://micrlchorrera.blogspot.com.br/2014/04/la-microcentralHidroeléctrica-la.html 
cial y económica a los efectos del conflicto armado ${ }^{23}$. Dentro de estos argumentos fueron recurrentes también los relacionados a la "deuda social y ambiental” del municipio de San Carlos, dados los impactos de las grandes centrales hidroeléctricas construidas allí en los años setenta y ochenta. "San Carlos y el Oriente antioqueño ya cumplieron con su cuota de aporte al desarrollo del país. Por lo tanto, no es justo seguir sacrificando más territorio" ${ }^{24}$.

También fueron recurrentes los argumentos en relación con los efectos e impactos del conflicto armado en el municipio, las graves afectaciones que tendría la construcción de la hidroeléctrica en los planes de retorno y en las garantías para este, y en general, en la falta de consulta y de socialización del proyecto, que se engloba en la carencia de una participación real y efectiva de los pobladores. Finalmente, Cornare, después de tres recursos de reposición, de la recolección de firmas contra el proyecto y luego de una marcha en el casco urbano y de actividades culturales que realizaron los habitantes del municipio de San Carlos,

23 El proyecto de turismo para la paz "Fortalecer y consolidar una Red de Turismo de base comunitaria para la región del Oriente antioqueño" fue construido en el contexto del segundo Laboratorio para Paz del Oriente antioqueño, buscando "diseñar e implementar acciones locales y regionales desde el turismo rural responsable y comunitario (ecoturismo), en la perspectiva de desatar procesos de desarrollo en clave de sostenibilidad social, económica y ambiental en trece municipios del Oriente antioqueño"; para ello, propone "construir cohesión social, reconocimiento y valoración del turismo rural, priorización de la planificación y ordenación del territorio en lo turístico e incorporación de actividades económicas innovadoras complementarias a las existentes, en las distintas localidades donde se desarrolla el proyecto" (Prodepaz, 2008, p.91). Este proyecto también busca contribuir al desarrollo territorial y a la cohesión social de la región e incrementar el nivel de ingresos y el bienestar social de las familias afectadas por el conflicto armado en trece municipios del Oriente antioqueño. "Los municipios participantes están localizados en las subregiones de Altiplano, Bosques, Embalses, Páramo y Porce-Nus del Oriente antioqueño, algunos de ellos en áreas de alta complejidad político-social, pero de incalculable riqueza ambiental, cultural y paisajística para el desarrollo de la actividad turística rural” (Prodepaz, 2008, p.92).

24 Intervenciones de la comunidad que se encuentran en el acta de la audiencia pública de carácter ambiental del proyecto denominado "PCH La Chorrera de Puerto Rico, ubicada en el municipio de San Carlos", realizada el 18 de abril de 2013 (Cornare, p.14). 
decidió revocar la licencia ambiental otorgada a este proyecto, sobre el argumento de la incompatibilidad con las zonas de bosques municipales y con las zonas de conservación ambiental declaradas por el consejo municipal, señalando, sin embargo, que los demás argumentos contra el proyecto fueron tomados en cuenta por Cornare a la hora de otorgar la licencia ambiental; asimismo, que en el EIA "se evidencia el interés de trabajo con los habitantes del área de influencia” ${ }^{25}$ y que en este documento se contaba con un programa de desarrollo local turístico y con las debidas acciones de mitigación y compensación.

Por otra parte, uno de los proyectos que se realizan en la subregión de Páramo es Hidroarma, que incluye la construcción de dos centrales hidroeléctricas con presa en el río Arma, la PCH Cañaveral y la PCH Encimadas, la primera con un potencial de generación de 80000 kW y localizada en el municipio de Sonsón y la segunda con un potencial de generación de 94000 kW y localizada en el municipio de Aguadas, departamento de Caldas. Las dos centrales hidroeléctricas son construidas por la empresa Hidroarma s.A., una sociedad mixta propiedad del Instituto para el Desarrollo de Antioquia IDEA. Estos dos proyectos, que ya cuentan con licencia ambiental y están próximos a ser construidos, han generado el rechazo general de la comunidad por los impactos en la producción agrícola y en la soberanía alimentaria, dada la poca socialización del proyecto con las comunidades y debido también a la expropiación, que ya comenzó a efectuarse a campesinos de las tierras necesarias para la construcción de estos proyectos. Según el Movete, no se socializa ni se informa a las comunidades adecuadamente sobre los proyectos, y cuando estos ya obtienen la licencia ambiental, se amenaza a los campesinos con la expropiación: "Amenazaron con la expropiación a quienes se opusieran a la venta de tierras” (Olaya, 2015, p.18). La figura legal que se utiliza para justificar la expropiación es la figura de utilidad pública e interés social, instrumento que respalda a

25 Ver Resolución 1120719 de Cornare, "Por medio del cual se procede a resolver un recurso de reposición”, del 4 de marzo de 2014. 
los proyectos de interés nacional y estratégico - Pines-, dentro de los cuales se incluyen los proyectos de minería y de hidroeléctricas y que fue otorgada para estos dos proyectos hidroeléctricos.

Un caso similar se presenta con la construcción de la PCH El Popal, ubicada en el municipio de Cocorná, con una capacidad instalada de $20000 \mathrm{~kW}$ y llevada a cabo por la empresa internacional Helm Group Company HBI Banca de Inversión junto con la empresa HMV Ingenieros. Con la construcción de esta PCH también se presentaron conflictos en relación con el aumento de los deslizamientos debido a fallas geológicas, el desabastecimiento de agua de varias veredas, la afectación a actividades sociales y económicas (por causa de los deslizamientos se vio afectado un "trapiche” para el procesamiento de la caña de azúcar y la generación de panela) y las expropiaciones de algunos predios rurales (Olaya, 2015).

Entre los municipios de San Luis y de San Francisco en el río Calderas (afluente que ya se encuentra intervenido con la PCH Calderas construida en los años ochenta) se encuentra en construcción la central hidroeléctrica a filo de agua San Miguel, proyecto con una capacidad instalada de 44000 kW, propiedad de la empresa Helm Group Company HBI Banca de Inversión junto con la empresa HMV Ingenieros. Al proyecto fue otorgada la licencia ambiental en 2012 y fue declarado como proyecto de utilidad pública e interés social el mismo año, exacerbándose los conflictos y la oposición de los pobladores en el momento en que comenzaron las obras de construcción de este proyecto. De hecho, por la oposición de los pobladores, la construcción fue detenida durante un año, reanudándose finalmente en el año 2013. Hay casos constantes de destrucción de bienes públicos y privados y de pérdida de caminos veredales que utilizaban los campesinos, así como denuncias sobre el débil seguimiento que Cornare hace al proyecto y a la construcción y también sobre la afectación histórica que las comunidades, especial- 
mente de la vereda El Pescado (con influencia directa del proyecto), han sufrido por causa del conflicto armado ${ }^{26}$.

A pesar de que las micro, mini y pequeñas centrales hidroeléctricas construidas a filo de agua son el centro de muchos de los conflictos que se presentan actualmente en el Oriente antioqueño, aún se presentan conflictos debido a la construcción de grandes centrales hidroeléctricas con embalse como es el caso del proyecto Provenir II, que espera intervenir el río Samaná Norte entre los municipios de San Carlos, Puerto Nare, Caracolí y San Luis. Este proyecto es propiedad de la empresa Celsia del grupo Argos y espera generar 352 MW, inundando 1902 hectáreas. Este proyecto se encuentra dentro de los proyectos Pines y cuenta, por lo tanto, con la declaratoria legal de utilidad pública e interés social, lo que lo "blinda" desde todos los aspectos legales. El Movete y las comunidades organizadas han llevado a cabo una lucha y una reivindicación contra este proyecto basándose principalmente en los impactos que la población del área de influencia sufrió con el conflicto armado en la década anterior. De esta manera, las veredas más afectadas por la guerra, en relación con desplazamientos y desapariciones forzadas, ahora se ven afectadas por el riesgo de despojo y de desapropiación que presupone este proyecto hidroeléctrico, ignorando de esta forma los procesos de atención a víctimas del conflicto armado y retrocediendo en los planes de reparación colectiva de la población.

Si bien en el Oriente antioqueño los conflictos socioambientales en su mayoría se centran en la generación de energía, no dejan de ser preocupaciones latentes la minería y los títulos mineros que existen en esta

26 Según Olaya (2015), la vereda El Pescado es “una de las más afectadas por el conflicto armado ya que hubo asesinatos, masacres y desapariciones forzadas, ante lo cual esta población fue desplazada en su totalidad” (p.17). La Personería municipal de San Luis afirma también que "la vereda El Pescado, área de influencia directa del proyecto, se encuentra en situación de extremo abandono. Esto es más grave aún si se entiende que más allá de una condición de pobreza estructural, sufrió afectación grave del conflicto armado” (Personería Municipal de San Luis, 2015, p.13). 
subregión. Resulta ejemplar la problemática que se vive en el corregimiento de Jerusalén, municipio de Sonsón, con la explotación de minas de gravas y calizas realizada por la multinacional $\operatorname{Argos}^{27}$ y que extrae aproximadamente 7200 toneladas de cemento al día (Olaya, 2015). Allí, las familias están siendo amenazadas por "un nuevo desplazamiento a nombre del desarrollo, esta vez representado por la explotación minera" ${ }^{28}$ y están siendo afectadas por la contaminación auditiva dados los constantes ruidos de la explotación-, por la contaminación del aire, por la utilización del amonio que genera impactos en la salud, especialmente de los estudiantes de una escuela que se encuentra a doscientos metros y de los pobladores que viven a menos de cien metros de las minas, por la pérdida de caminos veredales y la restricción de la movilidad, y por la pérdida de la soberanía alimentaria.

Antes de entrar esa empresa, esa fábrica, antes de montar esa planta ahí, las tierras eran buenísimas para nosotros sacar las cosechas, el maíz, el plátano, el frijol, vaya uno siembre ahora no da nada ya, debido a lo que han contaminado con lo que entran ahí para hacer el cemento, ahora quieren echarnos de ahí, no es justo, me parece a mí que no sea justo (Red de Acción Frente al Extractivismo, 2015) ${ }^{29}$.

A continuación, a partir de estos casos concretos de conflictos socioambientales, nos enfocaremos en dos temáticas que creemos fundamentales y que buscan profundizar tanto en las relaciones de poder del

27 A pesar que inicialmente los títulos mineros aparecen a nombre de empresas como Cementos Río Claro S.A., Procesadora de Cales Procecal S.A.S., Sociedad Asomardant, Minerales del Campo S.A.S., Ingetierras de Colombia S.A., Eurocerámica S.A., Cantera La Ceja S.A., Suministros de Colombia S.A., Alfagres S.A., Minerales Industriales S.A., Colombiana de Coloidales S.A., Cementos del Nare S.A., Vita Ltda., Estyma Estudios y Manejos Sociedad Anónima, en el Catastro Minero Colombiano - $\mathrm{CMC}$ - junto con estas empresas, en todos los títulos, aparecen las empresas Cementos Argos S.A. y Holcim.

28 Testimonio que se encuentra en el video de denuncia La piedra de Jerusalén, realizado por la Red de Acción Frente al Extractivismo, publicado el 20 de diciembre de 2015.

29 Ibid. 
neoextractivismo como en las relaciones de r-Existencia y movilización social: el neodesarrollismo neoliberal del "consenso de las commodities” y las luchas por justicia y deuda ambiental.

\section{Neodesarrollismo neoliberal del "consenso de las commodities"}

Desde de la formación histórica y geográfica del Oriente antioqueño, relacionada históricamente con la construcción de grandes centrales hidroeléctricas y de varias infraestructuras en los años setenta, y actualmente, con los megaproyectos de minería e hidroeléctricas, nos parece fundamental discutir los conflictos socioambientales actuales a partir de las formas de privatización-explotación-mercantilización de los bienes de la naturaleza que comienzan en los años noventa del siglo xx y que continúan, a la vez que se transforman, en la primera mitad del XXI. De esta manera, entendemos que la extracción minera a cielo abierto y las hidroeléctricas hacen parte de reconfiguraciones globales actuales en las dinámicas de poder y de acumulación de capital, en las que el sur global en general y América Latina, en particular, adquieren una importancia fundamental (Seaone, 2012). Así, las especificidades en la consolidación de la megaminería y de las hidroeléctricas en el Oriente antioqueño se entrelazan de forma compleja con las dinámicas globales, históricas y actuales, de poder y de acumulación.

Vimos, por ejemplo, que las primeras grandes centrales hidroeléctricas construidas en el oriente de Antioquia en los años setenta y ochenta no solo fueron iniciativa del Estado nacional y departamental, sino que también contaron con el apoyo económico y político abierto del BM y del $\mathrm{BID}^{30}$. La construcción de estas hidroeléctricas, por lo tanto, se rela-

30 Como señalamos anteriormente, todas las primeras hidroeléctricas construidas en el Oriente antioqueño en los años setenta y ochenta tuvieron el apoyo económico y político del Banco Mundial - BM- y algunas del Banco Interamericano de Desarrollo - BID- . Pero este apoyo económico y político no solo fue dado a las hidroeléctricas en esta región, sino también a otras grandes centrales hidroeléctricas 
ciona directamente con las dinámicas de reorganización socioterritorial del poder y de la acumulación a escala global que se consolidaron en estos años, y dentro de las cuales se impulsaron en América Latina procesos de liberalización de los mercados, políticas de desregulación y de privatización, que incluían los bienes naturales, fortalecimiento del sector financiero y agroexportador, entre otros procesos que se impusieron en su totalidad en los años noventa a partir del Consenso de Washington (Guiarracca y Teubal, 2013). La mercantilización del agua y de la energía, consolidada en esta época en varios países latinoamericanos y especialmente en Colombia, y que abrió el camino para la construcción de estas hidroeléctricas, constituye una clara muestra de estas dinámicas de reorganización socioterritorial del poder y de acumulación a escala global.

El neoliberalismo posibilitó así no solo la construcción de estas centrales hidroeléctricas, sino que también sentó las bases de la mercantilización de la naturaleza que vivenciamos en el presente, reconfigurada la ya tradicional economía primario-exportadora de América Latina (Guiarracca y Teubal, 2013). Para algunos autores, por lo tanto, el neoliberalismo, entendido como la reorganización socioterritorial de las relaciones de poder y de acumulación a escala global, fue la respuesta a la crisis sistémica de los años setenta — del periodo post Segunda Guerra Mundial-, así como a las iniciativas de control nacional estatal de los bienes naturales - especialmente el petróleo-, y de industrialización, - modelo de sustitución de importaciones ISI-, que estaban siendo construidas en la región ${ }^{31}$. Para reactivar las dinámicas de poder

construidas en otras partes del país, como la central hidroeléctrica de Anchicayá, localizada en el departamento del Valle del Cauca, y la central hidroeléctrica La Salvajina, localizada en el departamento del Cauca. Especialmente, la central hidroeléctrica La Salvajina contó con el apoyo del BID, pero además del fondo japonés Overseas Economic Cooperation, que otorga préstamos a países en desarrollo para proyectos estratégicos, el Export and Import Bank —Eximbank-, también de Japón, y el Banco Girozentrale de Austria. (Campaña Prohibido Olvidar, 2004).

31 Según Machado (2011), "el neoliberalismo - considerado como expresión de las estrategias de resolución a la crisis sistémica de los setenta ensayadas desde los 
y de acumulación a escala global en el marco de la crisis del sistema capitalista, el neoliberalismo en América Latina hizo un énfasis especial en la comercialización de las "materias primas", es decir, en el dominio y el control sobre los bienes naturales de la región (Machado, 2011). Las relaciones de poder a nivel mundial reconfiguran el papel estratégico de América Latina (Rodrigues y Gonçalves, 2013) y el imperialismo ecológico necesario para la acumulación y la expansión del capital. La consolidación de las bases institucionales y legales para la entrada y el desarrollo de capitales mineros globales en Perú, Ecuador y Bolivia en el año 1991 y en México en 1992 son una muestra de la centralidad que adquieren en el mapa de poder mundial los bienes naturales, en este caso minerales, de la región ${ }^{32}$.

centros mundiales de poder- puede ser entendido, en última instancia, como una profunda reorganización socio-territorial de la acumulación a escala global, en tanto dispositivo geopolítico destinado a redefinir las modalidades del imperialismo ecológico" (pp.150-151), y continúa: "las políticas ‘nacionalistas' de los países periféricos no solo alimentaron una crisis a nivel del régimen mundial de poder sobre el que se asienta la dinámica de la acumulación capitalista, sino también una crisis de gobernabilidad al interior de las sociedades centrales, las cuales en buena medida resolvían su ecuación de gobernabilidad mediante la exacerbación consumista, 'externalizando' su peso ecológico a los países dependientes” (p.154). Seaone (2012), por su parte, afirma que "la crisis económica internacional abierta a fines de 1929 y su prolongación en la Segunda Guerra Mundial supuso una alteración -más o menos profunda según los países- de la matriz primario-exportadora de las economías latinoamericanas y la aparición de los proyectos de industrialización en la región [...]. La transformación neoliberal a partir de los años setenta puso fin a esa fase del capitalismo y del sistema mundo de posguerra y, en sus particulares consecuencias en nuestra región, supuso un proceso de desindustrilización relativa, reprimarización económica y recolonización que sentó las bases del actual modelo extractivo exportador" (p.4).

32 El caso de Chile, por ejemplo, es particular en la medida en que fue el primer país en América Latina en consolidar estas bases institucionales y legales para la entrada de capitales mineros en el país durante la dictadura de Pinochet (1973-1988). Colombia también es un caso particular, ya que consolidó estas bases en 2001, tardíamente en relación con otros países latinoamericanos, lo que Vicente et al. (2011) relacionan con los enfrentamientos armados que se desarrollaban en varias partes del país y que atrasaron la entrada de las multinacionales en los territorios. 
Enredado complejamente con este proceso político y económico del neoliberalismo (Grosfoguel, 2008; Gómez y Grosfoguel, 2007), existe desde los años cincuenta, en el periodo post Segunda Guerra Mundial, una reactualización del discurso del progreso, representado en el auge del pensamiento del desarrollo que tuvo como punto simbólico de partida el discurso pronunciado por el presidente Truman en $1949^{33}$. A partir de esta coyuntura política, fueron sentándose y consolidándose en la segunda mitad del siglo Xx —en paralelo con las políticas neoliberales - las bases de este gran relato homogeneizante: el crecimiento, la productividad y la modernización (Svampa, 2012). Así, junto con el relato del desarrollo también nace el relato del subdesarrollo y del tercer mundo, de manera que va renovándose la creencia de que los países pobres, dentro de los que se incluyen los de América Latina, deben seguir un "recetario" de políticas y propuestas para alcanzar el desarrollo y los niveles de vida e industrialización de los países del primer mundo (Quintero, 2015).

Estas estructuras, embrolladas complejamente con el desarrollo y el neoliberalismo, han ido renovándose y transformándose con el paso del tiempo, configurando el actual neodesarrollismo neoliberal de Colombia y de otros países de América Latina como Perú y México. Debido a nuevas crisis en el sistema capitalista, que Harvey (2005) y Seaone (2012) atribuyen al desplome de los activos inmobiliarios en Estados Unidos, la especulación financiera se traslada, aproximadamente desde

33 Según Quintero (2015), en el periodo post Segunda Guerra Mundial que consolida a Estados Unidos como principal potencia hegemónica, se reestructuran las relaciones internacionales y se modifica la idea/fuerza del desarrollo. Dentro de esta reestructuración, se crean instituciones globales como el Fondo Monetario Internacional y el Banco Mundial, “encargadas de defender y fortalecer la acumulación mundial de capital y mantener sus desigualdades”. La idea/fuerza de desarrollo va a configurarse como una de las orientaciones motrices de este nuevo orden mundial, colocándose en un espacio central dentro de los procesos de reconfiguración global, tanto en el funcionamiento del sistema capitalista como en las formas de clasificación social [...]. El discurso de Harry Truman en 1949 será el reconocimiento público del lugar alcanzado por la vieja novedad del desarrollo” (p.142). 
2005, a los bienes de la naturaleza, incrementando el precio y valorizando las commodities de América Latina. Según Svampa (2012), este proceso marca un cambio en el modelo de acumulación, pasando del Consenso de Washington al "Consenso de las commodities", en el que, debido al boom en los precios internacionales de materias primas, se intensifica el control, la extracción y las exportaciones de bienes naturales y en el que surgen nuevas formas de dependencia y dominación y se profundizan las dinámicas de desposesión y despojo de tierras y territorios ${ }^{34}$.

Las características principales que asume este neodesarrollismo neoliberal en el Consenso de las commodities se basan en la generalización del modelo extractivo exportador, en la intensificación de los procesos de privatización-mercantilización-explotación de la naturaleza y de la vida, en la gran escala de los emprendimientos y, por lo tanto, en los mayores riesgos e impactos socioambientales - amenaza seria a la sustentabilidad ecológica planetaria-, en el aumento de la dependencia de los espacios socioproductivos locales al mercado internacional, en una demanda mayor de los países “desarrollados” a los países dependientes de materias primas, en la expansión de la frontera hacia territorios considerados improductivos, en la altísima fragmentación social y

34 Svampa (2012) propone el término de "Consenso de las commodities" para referirse a los procesos actuales de acumulación en América Latina caracterizados por la intensificación de los procesos de explotación de la naturaleza y por la intensificación de nuevas formas de dependencia y de dominación, así como de despojo de tierras y territorios, pero también para resaltar "la consolidación de un sistema de dominación, diferente al de la década de 1990, pues refiere menos a la emergencia de un discurso único, que desestima el rol de las ideologías o celebra el neoliberalismo como horizonte insuperable de nuestra época y alude más a una serie de ambivalencias y paradojas, que marcan la coexistencia y el entrelazamiento entre ideología neoliberal y neodesarrollismo progresista” (p.21). De esta manera, el neoextractivismo del Consenso de las commodities no solo está ligado al neodesarrollismo neoliberal de países como Colombia, Perú y México, sino también al progresismo latinoamericano reciente, en el que el discurso del desarrollo se adapta para justificar una matriz extractiva sobre bases nacionalistas y supuestamente redistributivas. Por lo tanto, podríamos hablar también de neodesarrollismo progresista. 
regional, en la devastación de las formas económicas y sociales existentes - reorientación de la economía de pueblos enteros y de sus estilos de vida-, en la violación sistemática a los derechos humanos y en el surgimiento y consecuente expansión de los movimientos socioambientales (Svampa, 2012; Svampa y Antonelli, 2009).

Dentro de estas características nos parece fundamental rescatar tres puntos importantes que nos ayudan a comprender el caso del Oriente antioqueño. El primero es la alta y creciente concentración y centralización de capitales del neodesarollismo neoliberal. De esta manera, se aumentan la importancia del capital transnacional y la concentración del poder en pocas megacorporaciones ${ }^{35}$, así como la movilidad espacial adquirida por el gran capital transnacional y nacional. Así, los capitales traspasan las fronteras nacionales, llegan a los territorios locales convirtiendo estos en unidades productivas privadas, en espacios "vacíos" y mercantilizables, permanecen por un tiempo y parten después en busca de nuevos mercados de explotación y de consumo, dejando, sin embargo, estos territorios en la mayor devastación y desolación, característica de los paisajes de la acumulación por desposesión de la periferia capitalista (Harvey, 2005).

El segundo es el uso de tecnologías de punta y la innovación técnica como característica fundamental de este modelo de acumulación. De esta manera, crecen y se consolidan nuevas técnicas de extracción y explotación como la minería a cielo abierto y las centrales hidroeléctricas a filo de agua y sin embalse. De las clásicas explotaciones de socavón, asistimos actualmente a los procesos de detección por satélite de los minerales, de "sofisticados" mapeos topográficos y geográficos —con el objetivo de identificar el grado de diseminación de los materiales-,

35 Esto es evidente en el caso de Holcim, empresa transnacional de Suiza, Anglogold Ashanti, empresa transnacional de Sudáfrica, Helm Group Company, de Estados Unidos y, en el caso también de empresas colombianas, Argos, la cual fue absorbiendo poco a poco y desde los años noventa varias cementeras colombianas en un proceso claro de centralización y concentración de capital. 
de voladuras enteras del suelo - montañas convertidas en rocas- y de aplicación de sustancias químicas - cianuro, mercurio- licuadas con grandes cantidades de agua para la separación de materiales. La minería a cielo abierto es, por lo tanto, una técnica de explotación intensiva y desmesurada en el uso de bienes de la naturaleza, no solo del subsuelo, tierra y minerales, sino también de agua y energía (Svampa y Antonelli, 2009).

En el caso de las centrales hidroeléctricas, actualmente van perdiendo importancia las grandes centrales con embalse para ganar en relevancia y expansión las pequeñas y micro centrales hidroeléctricas. Este proceso hace parte de la deslegitimidad que adquirieron en los años noventa las grandes centrales hidroeléctricas con embalse, después del auge de estas construcciones impulsado por el BM en los años setenta del siglo anterior, no solo en Colombia y en el Oriente antioqueño, sino en varios países de América del Sur y del mundo. Efectivamente, gracias a grandes movilizaciones sociales que resaltaban los impactos socioambientales negativos de estas construcciones y que ponían en tela de juicio su legitimidad basada en la generación de "energía limpia”, la construcción de grandes centrales hidroeléctricas con embalse se redujo, y en su lugar, comenzaron a impulsarse nuevas técnicas para la generación de energía por medios hidráulicos ${ }^{36}$. Es así como se im-

36 El cuestionamiento a los efectos de las grandes centrales hidroeléctricas con embalse comenzó a finales de la década de los noventa, cuando los impactos socioambientales y las consecuentes movilizaciones sociales en varias partes del mundo contra estas construcciones aumentaron y se hicieron imposibles de ignorar. Es así como el mismo BM incentivó la formación de un grupo de debate, que después se convertiría en la Comisión Mundial de Represas - CMR-, para analizar los aspectos controversiales asociados a la construcción de grandes represas. En los informes de esta comisión se hacen evaluaciones a los desempeños de las grandes represas, se resalta la necesidad de acrecentar el desarrollo humano sostenible, se incentiva la búsqueda de opciones para expandir los servicios de agua y energía (dentro de las que se resaltan las opciones de pequeña generación), se proponen opciones para la disminución de los impactos socioambientales y se reconoce la importancia de obtener la aceptación pública de los proyectos. Para más información, ver: Comisión Mundial De Represas (2000). Represas y desarrollo: un nuevo marco para la toma de decisiones. Reporte final de la Comisión Mundial de 
pulsaron las construcciones a filo de agua, que basan su potencia en el caudal del río y no en la acumulación artificial del agua, a diferencia de las centrales hidroeléctricas con embalse que no dependen del caudal y cuya capacidad de generación es más constante y continua (Godoy, 2013). Estas construcciones se impulsan teniendo como base la reducción de los impactos socioambientales que generan las grandes centrales con embalse, ya que no es necesario inundar grandes cantidades de tierra, lo que sin embargo no significa que haya una reducción real de sus efectos, teniendo en cuenta que se construyen con la misma racionalidad economicista del capitalismo neoliberal.

El tercer punto que queremos resaltar es el papel que asume el Estado en el neodesarrollismo neoliberal. En este modelo de acumulación, los Estados nacionales profundizan las características del Estado metaregulador, encargado de abrir espacios para los reguladores no estatales, constituyéndose como un simple actor más y dejando en manos de las empresas transnacionales la reglamentación de varios aspectos de la vida social. De esta forma, los Estados nacionales son los encargados de viabilizar la entrada de las empresas a los territorios, mediante la modificación de legislaciones y políticas ambientales, otorgando las garanticas jurídicas y fiscales que permiten la consolidación de estas en los territorios, construyendo las infraestructuras y organizando los espacios para adecuarlos al mercado internacional de las commodities (Zhouri y Laschefski, 2010).

Si bien los Estados nacionales - y en este caso, el colombiano- no son estructuras homogéneas ni estáticas, ya que presentan contradicciones e incoherencias internas y entran algunas veces en relaciones contradictorias con las empresas (Harvey, 2014), la mayoría de las veces anidan sus esfuerzos para crear las bases institucionales y territoriales que atraigan al capital extranjero (Zhouri y Laschefski, 2010), presentando este proceso bajo las perspectivas del neodesarrollismo neoliberal. La política de “confianza inversionista” del expresidente Álvaro Uribe Vé-

Represas, versión original en inglés en el Reino Unido y Estados Unidos. Earthscan Publications Ltd. 
lez es una clara muestra de la organización del espacio desde el Estado colombiano en pro de los proyectos extractivos y de las dinámicas de poder y de acumulación global.

Así, encontramos que en Colombia, a partir del año 2001 comienzan, desde el Estado nacional, a sentarse las bases para la entrada de capitales transnacionales en la minería con la creación del Código Minero, y que años después, aproximadamente desde el 2007 —una entrada tardía debido a la situación de conflicto armado que vivía la región-, en el Oriente antioqueño se renuevan los intereses extractivistas representados en la gran minería y en la construcción de grandes, pequeñas y microcentrales hidroeléctricas. Estos emprendimientos son vistos desde el Estado nacional y departamental como las claves del desarrollo, tal como puede observarse en los planes de desarrollo departamentales - "La presente administración departamental se propone como meta incentivar el desarrollo minero para que el aporte al PIB de Antioquia llegue al 2,4\% y que se generen al menos 25 mil empleos en el sector" (Gobernación de Antioquia, 2008, p.164) - y en los planes de desarrollo nacionales - “El sector minero-energético seguirá siendo uno de los motores de desarrollo del país, a través de su aporte al crecimiento económico, al aparato productivo, al empleo rural y a la inversión privada” (Departamento Nacional de Planeación, 2015, p.140)—.

Finalmente podemos decir, a partir de estas características y puntos resaltados, que esta dinámica de privatización-mercantilización-explotación de los bienes naturales en el neodesarrollismo neoliberal no puede tener otro resultado que el de aumentar las tensiones sociales, los conflictos socioambientales y las resistencias en América Latina (Zhouri y Laschefski, 2010). Este modelo, que tiene sus bases en la intensificación y en la constante recreación de formas de dominación sobre la naturaleza y los territorios, no solo genera la devastación de los bienes naturales, sino que, de forma paralela, degrada la vida y la dignidad humanas. El proceso de mercantilización del mundo presupone así la reducción de la naturaleza y de la vida humana a meras mercancías, y 
ratifica la siniestra dominación de la naturaleza a la vez que destruye la capacidad de los seres humanos de afirmarse fuera de la lógica mercantil capitalista (Harvey, 2014). Es debido a esto que evidenciamos en el Oriente antioqueño el crecimiento actual de los conflictos y de las r-Existencias, por lo que a continuación nos acercaremos a las lógicas históricas y espaciales enmarcadas en las luchas por justicia ambiental y por los significados otros de la naturaleza.

\section{Justicia y deuda ambiental y significados otros de la naturaleza}

Uno de los aspectos más importantes que pudimos observar en las resistencias históricas y actuales del Oriente antioqueño fue la lucha por justicia ambiental, la cual se enmarca primordialmente en una reivindicación por la distribución equitativa de los beneficios y de los perjuicios de los grandes proyectos extractivos. La lucha contra la desigualdad ambiental se basa en la distribución desigual de poder en la apropiación de bienes de la naturaleza, así como en "la capacidad diferenciada que tienen los agentes de producir impactos indeseables para toda la sociedad y para los grupos más vulnerables en particular” (Coletivo Brasileiro de Pesquisadores da Desigualdade Ambiental, 2012, p.165).

De esta manera, y como lo señala Porto-Gonçalves (2006), cuando se pide a toda la sociedad que ahorre agua o energía o que haga su parte, se está desconociendo que los grupos sociales que se benefician de las dinámicas de poder también son responsables por los impactos socioambientales, contaminación, derrumbes, enfermedades, desplazamientos, destrucción de relaciones de sustento de la vida, de sistemas socioculturales y de dinámicas territoriales que causan los grandes proyectos. Así, los grupos sociales que se benefician de las relaciones de poder -en este caso, las empresas transnacionales y nacionales que llevan a cabo los proyectos y el Estado nacional, específicamente, en sus alianzas público-privadas - no solo son los responsables directos de los impactos socioambientales de los grandes proyectos, sino que, 
además, son los culpables de la distribución espacial inequitativa de estos impactos (Coletivo Brasileiro de Pesquisadores da Desigualdade Ambiental, 2012).

Por lo anterior, a la dinámica de separación espacial de los centros de producción de materias primas de los centros de transformación e industrialización, que caracteriza el proceso de división internacional del trabajo, se le agrega también la separación espacial de los grupos sociales que se benefician económica y políticamente de los grandes proyectos extractivos de aquellos que tienen que soportar los impactos y los perjuicios que inevitablemente estos proyectos generan, ya que se encuentran basados en una visión de dominio-explotación de los bienes naturales y, por lo tanto, de su inevitable destrucción y devastación. Es así como, en los países de la periferia, al igual que en las periferias y regiones límite de los territorios nacionales, se concentran los impactos y efectos del neoextractivismo y del neodesarrollismo neoliberal.

Vimos cómo, en el caso del Oriente antioqueño, los grandes proyectos de minería y de construcción de hidroeléctricas afectan nuevamente a los históricamente marginados, comunidades campesinas que derivan su sustento de la agricultura familiar y pescadores y mineros artesanales que habitan principalmente en los municipios del "oriente lejano y su periferia”. A este respecto, Olaya (2012) señala que las primeras grandes centrales hidroeléctricas construidas en los años setenta en esta zona no se levantaron allí solamente debido a las condiciones hidrológicas y topográficas favorables, sino también debido a que no se reconocieron las importantes relaciones territoriales, económicas, sociales y culturales que en estos lugares existían y se habían construido. Esta invisibilidad está en la base también de los beneficios y ganancias de los proyectos, ya que al asumir que no hay procesos de Existencia en los territorios, no hay necesidad de asumir los costos de los impactos socioambientales y, por lo tanto, la productividad aumenta.

La importancia de los cultivos de café, plátano, maíz, fríjol, tomate, arracacha, papa, yuca, frutales, cabuya y pastos, al igual que la minería y 
la pesca, sustento de los municipios más adelante afectados, fueron subestimados por los planificadores de las centrales hidroeléctricas. Mucho menos se consideró la afectación social que se iba a producir, acorde con la densidad de población campesina ubicada en estos lugares, lo mismo que los problemas climáticos y medioambientales que ocasionan las represas (Olaya, 2012, p.69).

De esta manera, es importante señalar que las comunidades campesinas y de pescadores y mineros artesanales ya se encontraban r-Existiendo en los territorios donde años después fueron construidas las primeras hidroeléctricas de los años setenta, y ya venían apropiándose de estos territorios mediante la espacialización de sus relaciones sociales, económicas y culturales, en un proceso intenso de "colonización” de estas tierras $^{37}$. Cuando estas comunidades producían y reproducían procesos

37 La "colonización antioqueña" es un nombre que se le asigna generalmente a un proceso de expansión de las élites antioqueñas en el siglo Xx ligado a la economía del café. Sin embargo, los procesos de "colonización" en varias partes del país y en el departamento de Antioquia también fueron procesos en los que campesinos pobres y sin propiedades se desplazaron en busca de tierras hacia otros territorios del país que hasta ese momento se encontraban geográficamente aislados o poco poblados, principalmente a finales del siglo XVIII y comienzos del siglo XIX (aunque también hubo una continuidad de este proceso en el siglo Xx). Estos procesos tienen en Antioquia una especificidad importante debido, por un lado, a la magnitud de familias campesinas que se desplazaron, y, por otro lado, a la importancia de las explotaciones auríferas coloniales que se realizaban allí y que también fueron uno de los ejes que impulsaron la movilidad de la población y la búsqueda de nuevas tierras. De esta manera, y teniendo también como marco la gran concentración de tierras que se configuró desde la época colonial, miles de familias campesinas pobres migraron en búsqueda de tierras y de nuevas minas de oro, construyendo en los nuevos territorios procesos de r-Existencia. Efectivamente, en los territorios a los cuales llegaban (principalmente la subregión del Suroeste Antioqueño y las regiones límites de los departamentos de Quindío, Caldas y Valle del Cauca), estas familias reprodujeron sus modos de vida, costumbres y tradiciones en un proceso profundo de apropiación territorial, mediante el cual se consolidó la pequeña propiedad campesina en contraposición a la gran concentración de tierras presente en el país. En el caso del Oriente antioqueño y de los municipios más cercanos al río Magdalena y más cercanos al departamento de Caldas, y por tanto más lejanos de Medellín y del centro del departamento, este proceso de colonización de tierras fue primordial y es una de las características principales de los procesos de apropiación territorial de los municipios de San Carlos, San Luis, San Rafael, Sonsón, Argelia 
de apropiación territorial y de Existencia, llegaron estos grandes proyectos a transformar intensa y drásticamente las relaciones que habían construido. Es en este momento cuando el sentimiento de injusticia en las poblaciones comenzó a generarse, inicialmente en los municipios que fueron afectados por estas obras -El Peñol y Guatapé- y después expandiéndose a gran parte del Oriente antioqueño, consolidándose así los movimientos cívicos en la región (Olaya, 2012; García y Aramburo, 2011).

De esta forma, los pobladores del Oriente antioqueño comenzaron a sentir que además de tener que soportar los impactos de la construcción de las hidroeléctricas, no recibían ningún tipo de beneficio y, por el contrario, tenían que pagar el costo de estas obras a través del cobro de la factura de la energía eléctrica. En este momento se construye el sentimiento de "colectividad injustamente tratada por el Estado" (García y Aramburo, 2011), que conllevó finalmente a la creación de los movimientos cívicos del Oriente antioqueño de los años setenta y ochenta. Efectivamente, la injusticia, ligada estrechamente con el sentimiento de imposición de proyectos “desde afuera” (García, 2007), va a ser una de las pautas fundamentales que desencadenará los procesos de movilización social en el Oriente antioqueño, no solo en esa época, sino también actualmente.

La fuerte movilización de los movimientos cívicos reveló la poca consideración o debate que hubo en torno a los reales riesgos e impactos de la construcción de grandes centrales hidroeléctricas, cuestionando la misma idea del desarrollo y del crecimiento que fue proclamada y auspiciada en relación con estos proyectos (Campaña Prohibido Olvidar, 2014). La movilización en el Oriente antioqueño también estableció como pauta fundamental la necesidad de participación de las comuni-

y Nariño. Para más información, ver: Lenis Ballesteros, César Augusto (2009). Las otras colonizaciones en Antioquia. El caso del nordeste antioqueño, 1824-1886. Historia y Sociedad, (16), 23-48. 
dades y poblaciones afectadas en la toma de decisiones sobre el qué y el cómo mitigar y compensar. Esta reivindicación vuelve a surgir actualmente en el Movete, donde se denuncia que las empresas imponen las medidas de compensación que les parecen apropiadas y las comunidades se ven obligadas a aceptar, pues o acceden a las indemnizaciones ofrecidas o simplemente no hay más ${ }^{38}$.

Pero las reivindicaciones en el Oriente antioqueño no son solo por justicia ambiental, también lo son por la deuda ambiental. Esta es otra forma de construir la lucha alrededor de la huella, de los efectos e impactos socioambientales ya ocasionados en el territorio y debido los cuales "no es justo seguir sacrificando más territorio" ${ }^{39}$. Desde esta perspectiva, el Oriente antioqueño ya ha dado su "cuota de impactos" en favor de ese desarrollo y no es justo continuar con la dinámica extractivista en una región que ya vivió la devastación y la cara oculta -o no tan oculta, en realidad-del neoliberalismo.

Pero, junto con estas reivindicaciones en torno a la justicia y deuda ambiental, se encuentra también otro punto fundamental: los significados otros de la naturaleza y del territorio que construyen históricamente los habitantes del Oriente antioqueño. En el Oriente antioqueño, una de las bases a partir de las cuales se construye la defensa por la vida y el territorio son los significados colectivos que se le atribuyen a ciertos espacios y que no responden a una lógica puramente mercantil o a una racionalidad moderna de explotación-privatización de la naturaleza, como lo observamos en los casos de conflictos por las pequeñas y microcentrales hidroeléctricas. De esta forma, la belleza del paisaje, de las aguas y de las montañas, la relación sociocultural establecida con los ríos como lugares de fiestas, de socialización comunitaria, de experien-

38 Información obtenida de entrevista realizada a Carlos Olaya, miembro del Movete, en trabajo de campo en Antioquia en abril de 2016.

39 Información obtenida en entrevista realizada a Evelio García, integrante del Movete, en trabajo de campo en Colombia y en el departamento de Antioquia en mayo de 2016. 
cias de vida, e incluso, las relaciones de producción-sustento de la vida percibidas como actividades ancestrales, como la agricultura, la pesca y la minería artesanal, son fundamentales para la movilización de las comunidades. Vimos cómo estas relaciones, basadas más en un valor de uso que en un valor de cambio, han sido construidas históricamente por años de Existencia, r-Existencia y movilización social (movimientos cívicos, movimiento Oriente Unido y movimientos por la paz) de los pobladores del Oriente antioqueño.

De esta forma, la defensa actual que hace Movete del "tejido social rural, de las costumbres, de la ancestralidad, de los lazos familiares, de la vecindad y de la amistad" (Olaya, 2015, p.18) se basa en la protección de relaciones socioculturales "que se forman y están informadas por las experiencias de vivir en un lugar específico” (Oslender, 2007), de manera que están ancladas espacialmente y se entrelazan de forma compleja con los espacios físicos y con los bienes naturales. Así, el espacio vivido, el espacio cotidiano de la Existencia y de la r-Existencia, el espacio de las experiencias de vida, individuales y colectivas se defiende de la misma forma que a las propias relaciones sociales, culturales y económicas de las poblaciones del Oriente antioqueño. "El río une a las personas, forja amistades" ${ }^{40}$, la cascada es "patrimonio natural y paisajístico del pueblo" ${ }^{41}$, “es un paisaje muy bonito lleno de selva”42; son testimonios que muestran la relación no mercantilista ni puramente

40 Testimonio de los habitantes de San Luis que se encuentran registrados en la sistematización que el movimiento Vigías del Rio Dormilón construyó de su proceso de lucha y reivindicación. El documento "Sistematización del proceso ciudadano por la protección y defensa del Río Dormilón”, fui facilitado por el movimiento Vigías del Rio Dormilón en trabajo de campo en Abril de 2016, pero aún no ha sido publicado oficialmente.

41 Testimonio obtenido de la noticia "La micro central hidroeléctrica La Chorrera (PCH) municipio de San Carlos” publicada el 22 de abril de 2014 por Dubier Felipe Herrera. http://micrlchorrera.blogspot.com.br/2014/04/la-microcentral-Hidroeléctrica-la.html

42 Entrevista realizada a Carlos Olaya miembro del Movete en marzo de 2016 en trabajo de campo. 
economicista con los bienes de la naturaleza mantenida por los pobladores del Oriente antioqueño, así como el entramado complejo que han construido las personas entre sí, y las relaciones con el espacio, de los seres humanos con la naturaleza, "lo que significa el río Samaná: comida, alegría, sustento, nuestra cultura de abuelos, de la familia, la familia es la unión de la comunidad [...] Somos como una especie más que depende de ese río"43.

De esta manera, los bienes de la naturaleza son parte integral de la totalidad de las relaciones sociales y comunitarias, son cómplices inseparables de los modos de vida de campesinos, pescadores y mineros artesanales: "para nosotros el río es todo, es nuestra vida, nuestra forma de vida, cuando hay subienda es la dicha de nosotros, toda la vida en este río, naciendo en una canoa"44. Por esto, la defensa de la vida es al mismo tiempo la defensa del territorio, la defensa de los bienes naturales es la defensa de todas las relaciones sociales, culturales, económicas; es la defensa de la Existencia, construida y consolidada en un lugar específico del mundo, un lugar pleno de sentidos y de experiencias de la existencia social, un lugar del que han sido desplazados, pero un lugar al que vuelven r-Existiendo y movilizándose. "Ellos dicen que nos reubican, pero ¿a dónde? Si uno es aquí donde tiene lo de uno, donde uno se crio y ahí tiene de dónde vivir” ${ }^{45}$.

En las reivindicaciones y luchas del Movete no está separada la lucha de la vida de la lucha por el territorio, de manera que la naturaleza y la vida no son vistas como objetos separados, como falsas disyuntivas;

43 Testimonios que se encuentran en el documental "Represando el Porvenir" de la serie documental Memoria y Territorio realizado por la Escuela de Creación Documental-Área de Comunicaciones de la Asociación Campesina de Antioquia ACA. Producciones EL RETORNO 2014

44 Ibid.

45 Ibid. 
son vistos así, en su totalidad, como naturalezavida ${ }^{46}$. De esta manera, la felicidad, el bienestar, la vida digna, las necesidades de la comunidad no pueden estar separados de la convivencia en armonía con la naturaleza (Movete, 2015), de la defensa de "nuestro río", de “nuestro páramo" 47 . La naturaleza y los bienes naturales adquieren aquí otro matiz, otra lógica de enunciación, otros sentidos que difieren de la racionalidad moderna y de la lógica de acumulación de capital que los convierte en recursos, en objetos predispuestos a la explotación y a la ganancia económica (Leff, 2014).

Todo lo anterior conlleva a que se apueste actualmente por el no rotundo a los proyectos hidroeléctricos y mineros en el Oriente antioqueño, relacionado con la experiencia histórica de Existencia y movilización social. De esta manera, por un lado, se tiene una experiencia en la lucha por justicia ambiental, que envuelve la lucha por mitigaciones y compensaciones, y por otro lado, se tiene una lucha por la deuda ambiental, enmarcada en una memoria territorial que encierra la huella dejada tanto por los impactos socioambientales del extractivismo en sus territorios como por las posibilidades de resistencia y movilización social; y, finalmente, se tiene todo un arraigo territorial enmarcado en significados otros de la naturalezavida, culturales, sociales, económicos y políticos. Todo lo anterior permite que se afiance el no a los proyectos neoextractivos, reivindicándose la lucha por la redistribución, tanto de las ganancias como de las pérdidas del neodesarrollismo neoliberal, así como también por el reconocimiento de los territorios que son apropiados y habitados por comunidades y poblaciones con modos de vida y Existencia particulares y específicos (Fraser y Honeth, 2006).

46 Unimos aquí las palabras naturaleza y vida para dar énfasis a la compleja relación entre las relaciones sociales y las relaciones que se establecen con el espacio y con la naturaleza y que son visibles en las resistencias del Oriente antioqueño.

47 Testimonio obtenido en la reunión mensual del Movete realizada el 5 de abril 2016 en el municipio de Rionegro. Esta alusión a nuestro paramo o a nuestro rio es constante en los testimonios y sistematizaciones del Movete y de las organizaciones sociales que hacen parte de este movimiento. 


\section{Consideraciones finales}

Con base en lo anteriormente señalado, presentamos las siguientes consideraciones finales sobre el neoextractivismo, sobre la r-Existencia y movilización social y sobre los conflictos socioambientales, teniendo en cuenta, principalmente, la experiencia concreta del Oriente antioqueño, y que buscan, más que concluir, abrir el debate académico y político sobre el neoextractivismo, la resistencia y los conflictos socioambientales en Colombia.

Sobre el neoextractivismo: pudimos observar que el neoextractivismo actual del Oriente antioqueño se relaciona con cambios en el modelo de acumulación, caracterizados por la profundización y exacerbación de relaciones de poder ya iniciadas en el neoliberalismo, especialmente aquellas referentes a la privatización-explotación-mercantilización de bienes de la naturaleza. En este artículo señalamos principalmente tres aspectos de este cambio en el modelo de acumulación: la concentración, centralización y creciente movilidad de los capitales; el uso de tecnologías de punta que buscan maximizar las ganancias y a la vez minimizar los impactos socioambientales (lo que pudimos observar con el auge de las micro y pequeñas centrales hidroeléctricas); y la profundización del papel metaregulador del Estado, que abre campo a los reguladores no estatales, otorgándoles gran importancia a las empresas multinacionales que se convierten en moderadores de gran parte de la vida social, es decir, verdaderos actores totalizantes.

Ver el neoextractivismo como una profundización de relaciones históricas y espaciales ya iniciadas en el neoliberalismo nos permite comprenderlo no solo a partir de las especificidades del actual modelo de acumulación, sino también como un proceso con ciertas continuidades enmarcadas en una lógica base, histórica y espacial, de relación con la naturaleza y con los otros, que hace parte de la modernidad, del capitalismo y el colonialismo. Si partimos de esta continuidad y de esta lógica base, podemos entender que dentro del neoextractivismo no solo 
se encuentra el tradicional extractivismo minero, sino también otras infraestructuras y proyectos que, aunque con especificidades, parten de la misma lógica de privatización-mercantilización-explotación de los bienes de la naturaleza, como las centrales hidroeléctricas. Bajo estas perspectivas cabe preguntarse sobre las relaciones y entrelazamientos entre distintos tipos de neoextractivismo y la minería, así como con las centrales hidroeléctricas, una pregunta fundamental en el caso del Oriente antioqueño.

Sobre la relación entre el neoextractivismo y la violencia: en el caso del Oriente antioqueño pudimos ver que el neoextractivismo no solo se basa en la privatización-mercantilización-explotación de bienes de la naturaleza, sino también en diversas violencias contra la vida humana. Las relaciones territoriales del conflicto armado colombiano y sus consecuencias se han entrelazado complejamente con el neoextractivismo, acallando violentamente las resistencias y las formas de organización colectiva que se han opuesto a este modelo. Además de lo anterior, el resurgimiento del neoextractivismo en el Oriente antioqueño se ha constituido como un impedimento y un retroceso para los planes de retorno de la población desplazada por el conflicto y para los planes de reparación colectiva e individual de las víctimas de la guerra.

Pero el neoextractivismo no solo se ha entrelazado con las violencias propias del conflicto armado. Esta lógica de relación con la naturaleza se basa también en violencias constantes apoyadas en el despojo, en las fuertes transformaciones en las dinámicas socioterritoriales propias, en la imposición de proyectos y de compensaciones, en la poca e ineficiente socialización y consulta con las comunidades, en la inexistencia de una real participación efectiva de los pobladores afectados y en una invisibilidad y constante invalidación de las relaciones de Existencia construidas territorialmente.

Sobre la r-Existencia y la movilización social: las dinámicas de transformación intensa y drástica que supusieron la construcción de las 
primeras hidroeléctricas en los años setenta revelan que desde esa época ya Existían procesos profundos de apropiación territorial que fueron invisibilizados por las relaciones de poder. Con la llegada de las hidroeléctricas, surgieron fuertes procesos de movilización social que partían de estas Existencias y que buscaban visibilizarlas y defenderlas. En la experiencia del Oriente antioqueño, si bien se han dado procesos de acallamiento violento de las movilizaciones sociales, pudimos ver que estas han resurgido constantemente, siendo posible identificar cuatro periodos fuertes de movilización: los movimientos cívicos, el movimiento Oriente Unido, los movimientos por la paz y el actual Movete. Estos periodos de movilización colectiva nos hablan de una relación fundamental que queremos resaltar: la relación intrínseca entre r-Existencia y movilización social. De esta manera, la movilización social se basa en procesos de Existencia en los territorios, en formas de ser y estar en el mundo, pero a la vez estas movilizaciones sociales han transformado y fortalecido también las r-Existencias ligadas al territorio. Esta relación compleja entre r-Existencia y movilización social permite ver que las relaciones que están en juego van mucho más allá de un derecho de petición, de una audiencia pública ambiental o de una marcha o de una protesta, es todo un entramado de relaciones espaciales e históricas construidas por los habitantes a partir de sus memorias colectivas y de su "estoque" de prácticas y experiencias. Este proceso intenso de subjetividad política hace parte de un arraigo territorial profundo de las comunidades del Oriente antioqueño, de una defensa en conjunto de la naturalezavida. Si realizáramos realmente una historia y una geografía de larga duración de la r-Existencia y de la movilización social, tal vez podríamos comprender el rotundo no actual a los proyectos neoextractivos y muchas de las dinámicas contraextractivas que se han venido tejiendo en el país.

Sobre los conflictos socioambientales: este neoextractivismo, con sus novedades y continuidades, y con su relación estrecha y compleja con diferentes tipos de violencia, claramente tiene como una de sus consecuencias la generación de una serie de conflictos socioambientales que 
surgen en contextos de asimetrías de poder, dentro de los que entran en tensión lógicas de privatización-mercantilización-explotación de la naturaleza con discursos y sentidos alternos de la naturaleza, ligados a las experiencias territoriales de vida, de r-Existencia y de movilizaciones sociales de las poblaciones que habitan estos territorios. La pregunta fundamental es cómo conciliar estas lógicas y sentidos, espaciales e históricos, construidos de forma diferenciada con la naturaleza y con la vida y cómo construir procesos de diálogos de saberes sin perder de vista las asimetrías históricas en las relaciones de poder. Lo que queda claro con la experiencia del Oriente antioqueño es que estas conciliaciones y diálogos no pueden partir de la invisibilidad e invalidación de los procesos de Existencia y de movilización social en los territorios ni de la imposición violenta y la ineficiente participación de las comunidades. Reconocer las deudas ambientales, los impactos socioambientales acumulados en los territorios y las deudas sociales, de subalternidad estructural y de los impactos del conflicto armado sería uno de los primeros pasos.

\section{Referencias}

Betancourt, Milson (2015). Adecuaciones espaciales para la dominación: conflictos modernos coloniales, territorios de vida en la amazonia andina y ejes de integración y desarrollo de la IIRSA (Tesis de doctorado). Universidad Federal Fluminense, Niteroi-RJ,

Campaña Prohibido Olvidar (2004). Privatización y derechos humanos, sector eléctrico en el Suroccidente Colombiano. Cali.

Castro-Gómez, Santiago y Grosfoguel, Ramón (2007). El giro decolonial: reflexiones para una diversidad epistémica más allá del capitalismo global. Bogotá: Universidad Javeriana.

Coletivo Brasileiro de Pesquisadores da Desigualdade Ambiental (2012). Desigualdade ambiental e acumulação por espoliação: o que está em jogo na questão ambiental? e-cadernos CES, 17, 164-183.

Corporación Jurídica Libertad (2015, mayo). El proyecto minero-energético en la región del Oriente antioqueño. Medellín, Colombia. 
Departamento de Planeación Nacional (2015). Visión Colombia II Centenario 2019-Plan Nacional de Desarrollo 2014-2018: Todos por un nuevo país.

Fraser Nancy y Honneth Axel (2006). ¿Redistribución o reconocimiento?: un debate político filosófico. Madrid: Ediciones Morata.

García, Clara Inés (2007, diciembre). Conflictos, discursos y reconfiguración regional en el Oriente antioqueño: de la violencia de los 50 al laboratorio de paz. Controversia, (189), 129-146.

García, Clara Inés y Aramburo, Clara Inés (2011). Geografías de la guerra, el poder y la resistencia. Oriente y Urabá antioqueños 1990-2008. Bogotá: Cinep-Odecofi, Iner-Universidad de Antioquia, Editorial Códice.

Giarraccca Norma y Teubal Miguel (Coords.). (2013). Actividades extractivas en expansión: ¿Reprimarización de la economía argentina? Buenos Aires: Antropofagia.

Gobernación De Antioquia (s. f.). Plan de desarrollo de Antioquia 2008-2011. Antioquia para Todos. Manos a la obra.

Godoy Ortega, Janeth Carolina (2013). Desde Paute hasta Coca Codo Sinclair. 40 años de hidroenergía en el Ecuador: discurso alrededor de cambio de matriz energética, (Tesis de maestría). Facultad Latinoamericana de Ciencias Sociales, Ecuador.

Grosfoguel, Ramón (2008, marzo). Para descolonizar os estudos de economia política e os estudos póscoloniais: Transmodernidade, pensamento de fronteira e colonialidade global. Revista Crítica de Ciências Sociais, (80), 115-147.

Grosfoguel, Ramón (2016, enero-junio). Del «extractivismo económico» al «extractivismo epistémico» y al «extractivismo ontológico»: una forma destructiva de conocer, ser y estar en el mundo. Tabula Rasa, (24), 123-143.

Harvey, David (2005, enero). El "nuevo" imperialismo: acumulación por desposesión. Buenos Aires: Clacso.

Harvey, David (2014). Diecisiete contradicciones y el fin del capitalismo. Quito: Editorial IAEN.

Instituto de Estudios Regionales (Iner) (2003). Oriente: desarrollo regional una tarea común universidad-región. Medellin: Universidad de Antioquia. 
Leff, Enrique (2014). La apuesta por la vida: imaginación sociológica e imaginarios sociales en los territorios ambientales del sur. México: Vozes Editora.

Machado, Horacio (2011). El auge de la Minería transnacional en América Latina: De la ecología política del neoliberalismo a la anatomía política del colonialismo, En: Héctor Alimonda (Org.). Naturaleza colonizada. Ecología política y minería en América Latina. Buenos Aires: Clacso, Ediciones Ciccus.

Machado, Horacio (2014). Potosí el origen: genealogía de la minería contemporánea. Buenos Aires: Mardulce.

Martins Rodrigues, Elvio (2007). Geografia e ontologia: o fundamento geográfico do ser. GEOUSP-Espaço e Tempo, (21), 33-51.

Menezes, Marilda y Malagodi, Edgard (2009). Os camponeses como atores sociais: a perspectiva da autonomia e da resistência. Campina Grande: Projeto IPODE/CNPq.

Movete (2015, septiembre). Del movimiento por la defensa de la vida y el territorio, $N$. 1. Oriente de Antioquia.

Observatorio de Paz y Reconciliación del Oriente antioqueño (2007). Estudio de diagnóstico y contextualizacion de los 23 municipios del oriente antioqueño sobre la situación del conflicto armado, los derechos humanos, el derecho internacional humanitario, las organizaciones sociales y la gobernabilidad democrática. Medellín.

Olaya, Carlos (2012). Nunca más contra nadie. Ciclos de violencia en la historia de San Carlos, un pueblo devastado por la guerra. Medellín: Cuervo Editores.

Olaya, Carlos (2015). Conflictos socio-ambientales en el Oriente antioqueño. Kavilando, 7 (1).

Oslender, Ulrich (2007). Revisiting the Hidden Transcript: Oral Tradition and Black Cultural Politics in the Colombian Pacific Coast Region. Environment \& Planning D: Society and Space, 25(6), 1103-1129.

Personería Municipal de San Luis (2015). Veeduría ciudadana de San Luis al proyecto hidroeléctrico San Miguel/HMV. Informe de gestión, enero 01 a abril 30. 
Porto-Gonçalves, Carlos Walter (2002). O latifúndio genético e a r-existência indígenocampesina. GEOgraphia, Revista da Pós-Graduação em Geografia da UFF, Niterói/RJ, IV(8), 39-60.

Porto-Gonçalves, Carlos Walter (2006). El desafío ambiental. México, D.F.: Programa de las Naciones Unidas para el Medio Ambiente, Oficina Regional para América Latina y el Caribe.

Porto-Gonçalves, Carlos Walter (2006, mayo). A geograficidade do social: uma contribuição para o debate metodológico para os estudos de conflitos e movimentos sociais na América Latina, Revista Eletrônica da Associação dos Geógrafos Brasileiros - seção três lagoas-MS, 1(3).

Porto-Gonçalves, Carlos Walter (2015). Pela Vida, pela Dignidade e pelo Território: um novo léxico teórico político desde as lutas sociais na América Latina/Abya Yala/Quilombola. Polis, Revista Latinoamericana, 14(41), 237-251.

Prodepaz (2008). Construyendo territorio. Sistematización de seis experiencias de región, desarrollo y paz. Rionegro: Impresol Ediciones Ltda.

Quintero, Pablo (2015). Antropología del desarrollo: perspectivas latinoamericanas. Buenos Aires: Kula Ediciones.

Rodrigues Mendonça, Marcelo y Gonçalves, Ricardo Júnior (2013). Os efeitos sócioespaciais dos grandes empreendimentos de mineração no cerrado em Goiás. Revista Territorial-Goiás, 2(2), 93-120.

Sáenz, Orlando (1986). Movimiento de pobladores y grandes proyectos hidroeléctricos. El caso del Peñol y Guatapé Antioquia. En Cuarto Seminario Internacional CEHAP - PEVAL. Medellín.

Seoane, José (2006). Movimientos Sociales y Recursos Naturales en América Latina: Resistencias al Neoliberalismo, Configuración de alternativas. Sociedade e Estado, 21(1), 85-107.

Seoane, José (2012). Neoliberalismo y ofensiva extractivista: Actualidad de la acumulación por despojo, desafíos de Nuestra América. Theomai, (26).

Svampa, Maristella (2011). Modelo de desarrollo y cuestión ambiental en América Latina: categorías y escenarios en disputa. En Fernanda Wanderley 
(Coord.). El desarrollo en cuestión: reflexiones desde América Latina. La Paz: Cides, Umsa.

Svampa, Maristella (2012). Pensar el desarrollo desde América Latina. En Gabriela Massuh (Ed.). Renunciar al bien común. Extractivismo y (pos) desarrollo en América Latina. Buenos Aires: Mardulce.

Svampa, Maristella y Antonelli, Mirta (2009). Minería transnacional, narrativas del desarrollo y resistencias sociales. Buenos Aires: Editorial Biblos Sociedad.

Unidad De Planeación Minero Energética (Upme) (2015). Atlas Potencial Hidroeléctrico de Colombia.

Vicente, Ana; Martin, Neil; Slee, Daniel; Birss, Moira; Lefebvre, Sylvain y Bauer, Bianca (2011, noviembre). Minería en Colombia: ¿A qué precio? Boletín informativo $n .^{\circ} 18$. РBI Colombia.

Zhouri, Andréa y Laschefski, Klemens (2010). Desenvolvimento e Conflitos Ambientais: Um Novo Campo de Investigação. Belo Horizonte: Editora UFMG. 